\title{
Seasonal climatology and dynamical mechanisms of rainfall in the Caribbean
}

\author{
Carlos Martinez $^{1,2}$ (i) $\cdot$ Lisa Goddard ${ }^{2} \cdot$ Yochanan Kushnir $^{1} \cdot$ Mingfang Ting $^{1}$
}

Received: 22 October 2018 / Accepted: 4 January 2019 / Published online: 14 January 2019

(c) The Author(s) 2019

\begin{abstract}
The Caribbean is a complex region that heavily relies on its rainfall cycle for its economic and societal needs. This makes the Caribbean especially susceptible to hydro-meteorological disasters (i.e. droughts and floods). Previous studies have investigated the seasonal cycle of rainfall in the Caribbean with monthly or longer resolutions that often mask the seasonal transitions and regional differences of rainfall. This has resulted in inconsistent findings on the seasonal cycle. In addition, the mechanisms that shape the climatological rainfall cycle in the region are not fully understood. To address these problems, this study conducts: (i) a principal component analysis of the annual cycle of precipitation across 38 Caribbean stations using daily observed precipitation data; and, (ii) a moisture budget analysis for the Caribbean, using the ERA-Interim Reanalysis. This study finds that the seasonal cycle of rainfall in the Caribbean hinges on three main facilitators of moisture convergence: the Eastern Pacific ITCZ, the Atlantic ITCZ, and the western flank of the North Atlantic Subtropical High (NASH). The Atlantic Warm Pool and Caribbean Low-Level Jet modify the extent of moisture provided by these main facilitators. The expansion and contraction of the western flank of NASH generate the bimodal pattern of the precipitation annual cycle in the northwestern Caribbean, central Caribbean, and with the Eastern Pacific ITCZ the western Caribbean. This study identifies the Atlantic ITCZ as the major source of precipitation for the central and southern Lesser Antilles, which is responsible for their unimodal rainfall pattern. Convergence by sub-monthly transients contributes little to Caribbean rainfall.
\end{abstract}

Keywords Climate variability $\cdot$ Precipitation $\cdot$ Large-scale dynamics $\cdot$ Caribbean

\section{Introduction}

The Caribbean is identified as a highly-vulnerable region to climate variability and change (Taylor et al. 2012). The region's vulnerability to climate is a result of a variety of factors including: limited human/natural resources; topography; densely populated coastal, low-lying urban areas; and, high-risk industries, such as tourism and agriculture (Taylor et al. 2012; Simpson et al. 2010; Lewsey et al. 2004; FAO 2016; OCHA 2015). Hydro-meteorological disasters such as multi-year droughts and floods have cost Caribbean countries hundreds of millions of dollars from water shortages and contamination which result in agricultural and energy

Carlos Martinez

carlos.martinez@columbia.edu

1 Lamont-Doherty Earth Observatory, Columbia University, 61 US-9W, Palisades, NY, USA

2 International Research Institute for Climate and Society, Columbia University, 61 US-9W, Palisades, NY, USA production losses that hamper economic growth and exacerbate the concurrent social issues (NOAA 2005; ODPEM 2010; FAO 2016; OCHA 2015, 2016). Numerous modeling studies have found systematic biases in the simulation of Caribbean rainfall (Ryu and Hayhoe 2013; Eichhorn and Bader 2017). These biases are attributed to an insufficient understanding of how small and large-scale atmospheric and oceanic processes interact to shape the seasonal rainfall pattern in the Caribbean. Therefore, better understanding and prediction of rainfall and its variability in space and time in the Caribbean is critical.

Situated from $5^{\circ} \mathrm{N}$ to $27^{\circ} \mathrm{N}$ and $60^{\circ} \mathrm{W}$ to $90^{\circ} \mathrm{W}$, the Caribbean region is a complex domain of tropical islands and large land masses surrounded by the Gulf of Mexico, the Caribbean Sea (CS), and the tropical North Atlantic. The climate dynamics of the region displays a unique range of competing interactions between mid-latitude and tropical features across spatial scales.

One of the large-scale features that impact the rainfall seasonal cycle in the Caribbean is the semi-permanent 
subtropical anticyclone known as the North Atlantic Subtropical High (NASH). NASH follows a semi-annual variability pattern with its peak intensity during the boreal summer as a maritime single-maximum pattern and a boreal winter feature with dual-maxima with one center over the subtropical Atlantic and another center over the North American continent (Davis et al. 1997). During these seasons NASH induces strong easterly trade winds and subsidence across the Caribbean region (Giannini et al. 2000; Wang and Lee 2007). The boreal Spring and Fall are characterized as transitional periods of NASH that result in weaker easterlies and weaker subsidence (Davis et al. 1997; Wang and Lee 2007).

Two important sources of rainfall in the Caribbean are the Intertropical Convergence Zone (ITCZ) and the South American Monsoon System (SAMS). The ITCZ is a zonally elongated tropical band of deep convection associated with confluent trade winds, high rainfall rates, and low pressures (Henderson-Sellers and Robinson 1986; Zhang 2001; Hastenrath 2002). Two branches of the ITCZ affect the Caribbean: the Atlantic ITCZ and the Eastern Pacific ITCZ. Their seasonal migrations follow the meridional movement of maximum solar radiation with a lag of 1-2 months (Mitchell and Wallace 1992; Waliser and Gautier 1993). Their northernmost extent occurs during early September and southernmost extent during early March. Unlike the Atlantic ITCZ and Eastern Pacific ITCZ, the land-based SAMS migrates in sync with the solar insolation cycle and is characterized by interactions between South American topography and ocean-atmosphere dynamics (Silva and Kousky 2012).

Additionally, the convection in the Caribbean is influenced by the location of the Western Hemisphere Warm Pool (WHWP) (Weisberg 1996; Wang and Enfield 2001). The WHWP refers to an area of regional SSTs warmer than $28.5^{\circ} \mathrm{C}$. The WHWP consists of two branches: the Eastern North Pacific Warm Pool and the Atlantic Warm Pool (AWP), the latter of which affects the Caribbean Basin (Wang et al. 2006). The AWP is absent during the winter. It appears off of the NW Caribbean in June. It then expands into the Gulf of Mexico in July, the western CS in August and the eastern CS in September. It begins to contract by October (Wang and Lee 2007). The onset and duration of the AWP is in sync with the onset and duration of the Caribbean rainfall season (Misra et al. 2014). Its emergence and expansion weaken NASH and its southwestern flank, and weakens upper-level westerlies over the Caribbean (Wang and Lee 2007). The regional warming of the AWP also enhances precipitable water in the Eastern Pacific ITCZ and western flank of the Atlantic ITCZ (Wang et al. 2008).

The NASH, ITCZ, and AWP and their interactions broadly shape the climatological summer rainfall pattern in the Caribbean (Giannini et al. 2000; Taylor and Alfaro 2005). With strong trade winds, subsidence, cool SSTs, and the southern migration of the ITCZ, the Caribbean is driest during the winter (Taylor and Alfaro 2005). Hence, these large-scale features are consistent and responsible for the region to be classified as "dry-winter tropical" (Rudloff 1981). During the summer rainfall season, on the other hand, these large-scale features compete, due to their interactions with regional-scale features and associated feedback mechanisms.

One such regional scale features is the Caribbean LowLevel Jet (CLLJ) (Amador 1998; Amador et al. 2000). Located between Northern South America and the Greater Antilles and extending across the western Caribbean, the CLLJ is a major transporter of moisture for the Caribbean and Central America (Durán-Quesada et al. 2010). The CLLJ is also an important component of circulation associated with the mid-summer drought, which is a short period of relatively dry conditions between two rainy intervals (MSD, Magaña et al. 1999; Herrera et al. 2015). Studies have attributed the genesis of the CLLJ to the intensification of easterly winds by NASH (i.e. Wang 2007; Cook and Vizy 2010) and its strength and orientation to be influenced by the AWP (Wang and Lee 2007), NASH (Cook and Vizy 2010), and topography (Muñoz et al. 2008).

Other summertime circulation features influencing rainfall in the Caribbean are African Easterly Waves (AEW) and tropical cyclones (TCs). AEWs are synoptic-scale perturbations, induced by the mid-tropospheric sub-Saharan jet, that propagate across the Atlantic Basin from mid-June to early October (Burpee 1972). These waves are a source of precipitation for the Caribbean, as these features account for more than half of all Atlantic TCs, and $\sim 85 \%$ of major hurricanes (Agudelo et al. 2011). TCs have a similar seasonal timeframe as AEWs; however, TCs peak in June and September, and have a minimum in July. In addition to AEWs, TCs can form from interactions with the Eastern Pacific ITCZ (Toma and Webster 2010), and emergence of the AWP (Wang et al. 2006). TCs can weaken from large vertical wind shear (Angeles et al. 2010), upwelling in the southwestern Caribbean (Inoue et al. 2002) and interactions with the CLLJ (Wang et al. 2008).

Other regional influences include a cyclonic sea-land circulation in Central America that displaces moist air into the Caribbean Sea (Poveda and Mesa 2000; Allen and Mapes 2017), mid-latitude troughs providing confluence from barotropic moist vs. baroclinic cold air masses (Reding 1992; Schultz et al. 1998; Giannini et al. 2000; Sáenz and DuránQuesada 2015; Allen and Mapes 2017), and a large body of warm, dry dusty air in the mid-troposphere, the Sahara Air Layer, that suppresses moisture (Carlson and Prospero 1972; Dunion 2011; Mote et al. 2017).

Localized mechanisms affect the magnitude of rainfall across various regions of the Caribbean. Sea breezes due to strong easterly winds by NASH, together with 
orographic lifting, provide rainfall on the leeward side of Caribbean islands and the Caribbean coast of Central America (Taylor and Alfaro 2005; Giannini et al. 2000; Hidalgo et al. 2015; Maldonado et al. 2018). Diurnal heating accompanied by warm SSTs also enhance convection in the Caribbean (Taylor and Alfaro 2005).

Only a handful of studies have investigated the observed spatial and temporal rainfall patterns in the Caribbean and identified large differences across different parts of the region (Giannini et al. 2000; Chen and Taylor 2002; Taylor and Alfaro 2005; Jury et al. 2007; Gamble et al. 2007; Curtis and Gamble 2007; Stephenson et al. 2014). Although most of these studies describe the seasonal rainfall cycle of the Caribbean as having a bimodal temporal pattern, many of these studies are inconsistent with each other when explaining regional differences. Some studies describe the seasonal rainfall as bimodal in the northwestern portion of the Caribbean and unimodal in the eastern Caribbean (i.e. Taylor and Alfaro 2005); others describe the opposite (i.e. Jury et al. 2007). Giannini et al. (2000) found the MSD to exist only in the central and eastern Caribbean, whereas Curtis and Gamble (2007) and Gamble et al. (2007) found the MSD to progress from the eastern Caribbean in May to Central America by July. These discrepancies are a result of spatial and temporal scales used in either the analyses or data that can mask the seasonal transitions and regional differences of the rainfall cycle. In addition, publicly available precipitation data at finer temporal resolutions in the Caribbean is sparse. As a result, longer time-scale averaged datasets are used to investigate the climatology of the Caribbean.

Furthermore, the relative influence dynamical mechanisms have on rainfall in the Caribbean is relatively unknown. Moisture budgets have been widely used to investigate sources and inhibitors of moisture globally (Trenberth and Guillemot 1995; Seager et al. 2010) and regionally (Huang et al. 2005; Jin and Zangvil 2010; Pomposi et al. 2015). However, to date there has not been a detailed moisture budget analysis for the Caribbean. Given that precipitation, evaporation, and net moisture transport into or out of an atmospheric column balance on timescales greater than 10 days (Brubaker et al. 1993), moisture budgets are useful in determining the hydrological cycle on a seasonal scale.

Here, we study the observational seasonal cycle of rainfall in the Caribbean using daily data and conducting a principal component analysis (PCA) to identify spatial and temporal variabilities. In addition, we study the total moisture budget of the Caribbean using the ERA-Interim Reanalysis (Seager and Henderson 2013). This analysis allows us to answer the following questions:

1. What are the regional differences of the seasonal cycle of rainfall across the Caribbean?
2. What are the local and remote dynamical processes that shape the spatial and temporal patterns of the seasonal cycle in the Caribbean?

The manuscript is structured as follows. Section 2 describes the data and methods used. Section 3.1 looks at the observed rainfall patterns of the Caribbean using the Principal Component Analysis. Section 3.2 details the results of a total moisture budget of the Caribbean. Section 3.3 breaks down the Caribbean into its climatological rainfall sub-regions based on the findings from 3.1 to 3.2. A summary, and proposed schematic of the dynamical mechanisms that influence rainfall in the Caribbean is found in Sect. 4. Finally, a discussion comparing this study with other studies, its significance, and future work are also found in Sect. 4.

\section{Data and methods}

\subsection{Data}

This study uses the Caribbean Institute for Meteorology and Hydrology (CIMH) 1969-2017 daily station rainfall. Given that some countries in the Caribbean are not member states of the Caribbean Meteorological Organization (CMO) from whom the CIMH's data originates, NOAA's Global Historical Climatological Network (GHCN) 1960-2017 daily station rainfall dataset is also used. Stations are data-stitched across the two observational datasets: station's missing data in one dataset is patched by the other dataset. This process is done only when the stations' coordinates between each dataset are within a $0.05^{\circ}$ margin from each other. The data are also checked for uniformity by analyzing overlapping years from each dataset. The combined CIMH/GHCN metadataset provides temporally finite historical precipitation data. A total of 38 stations are found, shown in Table 1, satisfying the requirements. In order to supplement the station data and validate the proposed regional classifications in the Caribbean, NASA's Tropical Rainfall Measuring Mission (TRMM) version 7 with $0.25^{\circ}$ by $0.25^{\circ}$ gridded daily precipitation estimate dataset (Huffman et al. 2007) is used.

For understanding the dynamical context of the seasonal hydrological cycle, the European Centre for Medium-Range Weather Forecasts Interim Re-Analysis (ERA-Interim) (Dee et al. 2011) is used to calculate the climatological moisture budget. The ERA-Interim is available at several resolutions. For this study, we used a spatial resolution of $1.5^{\circ}$ by $1.5^{\circ}$, a 6-hourly temporal resolution from 1979 to 2012 (2016 for SST), and 26 pressure levels. In the Caribbean, ERA-Interim bias with respect to the Global Precipitation Climatology Project estimate of precipitation amounts to of up to $\sim+2 \mathrm{~mm} /$ day, which presents a reduction of excess precipitation over evaporation 
Table 1 List of rainfall stations used in the study

\begin{tabular}{|c|c|c|c|c|c|}
\hline \multirow[t]{2}{*}{ Station ID } & \multirow[t]{2}{*}{ Station } & \multirow{2}{*}{$\begin{array}{l}\text { Location } \\
\text { Lat/Lon }\end{array}$} & & \multicolumn{2}{|l|}{ Data } \\
\hline & & & & $\begin{array}{l}\text { Valid years } \\
\text { (total years) }\end{array}$ & Missing data (\%) \\
\hline 1 & BC B. In. AP. Antigua and Barbuda & 17.135 & -61.791 & $46(57)$ & 0.79 \\
\hline 2 & Nassau Intl. AP., Bahamas & 25 & -77.5 & $43(48)$ & 5.89 \\
\hline 3 & CIMH, Barbados & 13.148 & -59.624 & $48(48)$ & 0.00 \\
\hline 4 & Grantley Intl AP., Barbados & 13.08 & -59.485 & $45(45)$ & 0.00 \\
\hline 5 & Cfarm, Belize & 17.2 & -89 & $40(48)$ & 2.45 \\
\hline 6 & Intl. AP., Belize & 17.53 & -88.3 & $52(57)$ & 0.33 \\
\hline 7 & Georgetown, Cayman & 19.3 & -81.3 & $45(50)$ & 0.41 \\
\hline 8 & Camaguey, Cuba & 21.24 & -77.51 & $50(56)$ & 0.80 \\
\hline 9 & La Habana, Cuba & 23.1 & -82.21 & $51(55)$ & 0.79 \\
\hline 10 & DCAP, Dominica & 15.547 & -61.2993 & $39(42)$ & 0.61 \\
\hline 11 & Santo Domingo, D.R & 18.25 & -69.58 & $25(57)$ & 26.33 \\
\hline 12 & Guadeloupe & 16.2 & -61.66 & $44(57)$ & 2.16 \\
\hline 13 & Georgetown, Guyana & 6.8 & -58.133 & $47(48)$ & 0.45 \\
\hline 14 & Time H.R.I, Guyana & 6.483 & -58.25 & $45(46)$ & 0.02 \\
\hline 15 & Worthy Park, Jamaica & 18.143 & -77.149 & $39(42)$ & 1.35 \\
\hline 16 & Intl. AP., Martinique & 14.59 & -60.99 & $56(57)$ & 0.14 \\
\hline 17 & Hewanorra Intl. AP., St. Lucia & 13.737 & -60.952 & $39(43)$ & 0.15 \\
\hline 18 & Dumbarton, St. Vincent & 13.18 & -61.17 & $43(48)$ & 3.17 \\
\hline 19 & Corantjinpolder, Suriname & 5.96 & -57.04 & $31(45)$ & 3.47 \\
\hline 20 & Zanderji, Suriname & 5.45 & -55.2 & $35(57)$ & 1.37 \\
\hline 21 & Piarco Intl AP, T\&T & 10.59 & -61.34 & $44(57)$ & 0.00 \\
\hline 22 & Crown Point, $\mathrm{T} \& \mathrm{~T}$ & 11.15 & -60.84 & $44(57)$ & 0.14 \\
\hline 23 & Sunset/Ft. Lauderdale, USA & 26.1 & -80.28 & $54(57)$ & 1.61 \\
\hline 24 & Key West, USA & 24.55 & -81.75 & $56(57)$ & 0.02 \\
\hline 25 & Miami Intl AP, USA & 25.82 & -80.28 & $57(57)$ & 0.00 \\
\hline 26 & Palm Beach AP, USA & 26.68 & -80.08 & $56(57)$ & 0.05 \\
\hline 27 & Henry E. Rohlsen AP, St. Croix & 17.7 & -64.81 & $39(44)$ & 2.55 \\
\hline 28 & Cyril E. King AP, St. Thomas & 18.33 & -64.97 & $25(43)$ & 9.65 \\
\hline 29 & Coloso, USPR & 18.381 & -67.157 & $38(57)$ & 2.61 \\
\hline 30 & Dora Bora, USPR & 18.336 & -66.667 & $42(57)$ & 6.68 \\
\hline 31 & Ensenda, USPR & 17.973 & -66.946 & $49(57)$ & 2.96 \\
\hline 32 & Guaynama, USPR & 17.978 & -66.087 & $35(57)$ & 9.61 \\
\hline 33 & Jajome Alto, USPR & 18.072 & -66.143 & $47(57)$ & 1.49 \\
\hline 34 & Mora Camp, USPR & 18.474 & -67.029 & $44(57)$ & 2.31 \\
\hline 35 & Paraiso, USPR & 18.265 & -65.721 & $44(57)$ & 3.34 \\
\hline 36 & Morovis N, USPR & 18.334 & -66.408 & $54(57)$ & 1.25 \\
\hline 37 & San Andreas, Columbia & 12.583 & -81.717 & $31(55)$ & 15.89 \\
\hline 38 & Felipe, Mexico & 19.7 & -87.9 & $32(57)$ & 12.73 \\
\hline
\end{tabular}

Station ID, station name, location in latitude and longitude, number of valid years from 1960 to 2017 that have valid pentad data, the total number of years available, and missing data. Missing data shows the percentage of pentads missing two or more days during total number of years compared to ERA-40 (Dee et al. 2011). We note however that the reanalysis precipitation is only used in a consistent context with the entire ERA-Interim based moisture budget analysis (see below).

\subsection{Methods}

\subsubsection{Pentad climatologies and PCA analysis}

Given the noise in daily data, pentad (5-day) averages of daily rainfall observations are calculated for each station. Using 
similar criteria from Hamada et al. (2002), if a pentad has two or more days of missing data, the pentad is omitted. If a pentad is missing or omitted within an analysis year, the entire analysis year is omitted for that station. Valid years for the analysis are given in Table 1. The rainfall pentad climatology for each station is calculated by averaging all valid years. After normalizing the pentad climatologies for each station, a Principal Component Analysis (PCA) is conducted, where the space dimension is the station number and the time dimension are the 73 pentads. The first three PCs are preserved and passed through a binomial filter for smoothing. The correlation coefficients between each stations' climatological seasonal rainfall cycle and PC are also calculated. A caveat is that the PCA analysis privileges more densely sampled areas, which is why the station pentad climatologies are shown in the analysis when distinguishing the regional classifications in the Caribbean. In addition, TRMM pentad climatologies for each of the regional classifications are calculated and compared with the station pentad climatologies in order to determine the authenticity of the classified regions. components: moisture convergence associated with the monthly mean circulation and moisture convergence associated with the submonthly transient eddies:

$\bar{P}-\bar{E}=-\frac{1}{g \rho_{w}} \nabla \cdot \sum_{k=1}^{K}\left(\bar{V}_{k} \bar{q}_{k}+\overline{V_{(6, k)}^{\prime} q_{(6, k)}^{\prime}}\right) \overline{d p}_{k}$,

where the first term in the summation on the right-hand side represents convergence by the mean flow, and the second term in the summation on the right-hand side represents convergence by 6-hourly transient flow. The primes on the second term denote daily departures from the monthly mean. Next, the divergence operator is moved to inside the summation in Eq. 3 in order to break down the mean flow convergence into its components. After calculating the climatological monthly and/or seasonal means, Eq. 3 can be rewritten as:

$\overline{\bar{P}}-\overline{\bar{E}}=-\frac{1}{g \rho_{w}}\left[\sum_{k=1}^{K} \overline{\left(\overline{q_{k}}\left(\nabla \cdot \overline{\boldsymbol{V}_{k}}\right)+\overline{\boldsymbol{V}_{k}} \cdot\left(\nabla \cdot \overline{q_{k}}\right)\right) \overline{d p_{k}}}+\nabla \cdot \sum_{k=1}^{K} \overline{\overline{\boldsymbol{V}_{(6, k)}^{\prime} q_{(6, k)}^{\prime} d p_{k}}}\right]-\overline{\overline{q \boldsymbol{V}_{s} \nabla p_{s}}}$,

\subsubsection{Moisture budget analysis}

The atmospheric moisture budget equation can be expressed as:

$P-E=-\frac{1}{g \rho_{w}} \nabla \cdot \int_{0}^{p_{s}} q \boldsymbol{V} d p$

In this equation, precipitation $(P)$ minus evaporation $(E)$ is equal to the convergence of the column integrated moisture flux (q $\boldsymbol{V}$, where q is specific humidity and $\boldsymbol{V}$ is the horizontal wind vector) multiplied by the scaling factor of gravity $(\mathrm{g})$ and density of water $\left(\rho_{w}\right)$. Following Seager and Henderson (2013), Eq. 1 is rewritten by taking its monthly time mean from 6-hourly intervals and put in $\mathrm{K}$ model pressure levels:

$\bar{P}-\bar{E}=-\frac{1}{g \rho_{w}} \nabla \cdot \sum_{k=1}^{K} \overline{\boldsymbol{V}_{(6, k)} q_{(6, k)} d p_{k}}$

where the overbars denote the monthly means. The righthand side of Eq. 2 denotes the convergence of the total moisture flux (TMF), or the net amount of convergence in the atmospheric column vertically integrated in $\mathrm{K}$ pressure levels. One can further break down the TMF into its two where the double bar represents the climatological monthly or seasonal mean. The first two terms on the right-hand side of Eq. 4 represents the mean moisture convergence due to mass convergence and mean moisture advection. The third term represents the climatological mean transient moisture convergence, and the last term is the surface term, which is related to the surface topography and the resulting surface pressure gradient. For this analysis the surface term is relatively small compared to other terms and is thus ignored.

\section{Results}

\subsection{Principal component analysis of the seasonal cycle of rainfall in Caribbean}

The first three principal components (PCs) explain $78 \%$ of the total variance $(54 \%, 16 \%, 8 \%$, respectively) of the pentad rainfall climatological seasonal cycle (Fig. 1a-c). The first principal component (Fig. 1a) displays the known seasonal characteristics dominant in the Caribbean: the Early-Rainy Season (ERS) beginning in late April and lasting through June, the MSD from June through August, the Late-Rainy Season (LRS) from August through late October, and the Winter Dry Season (WDS) from mid-November to April. In addition, the maximum rainfall occurs during the LRS 
(a)

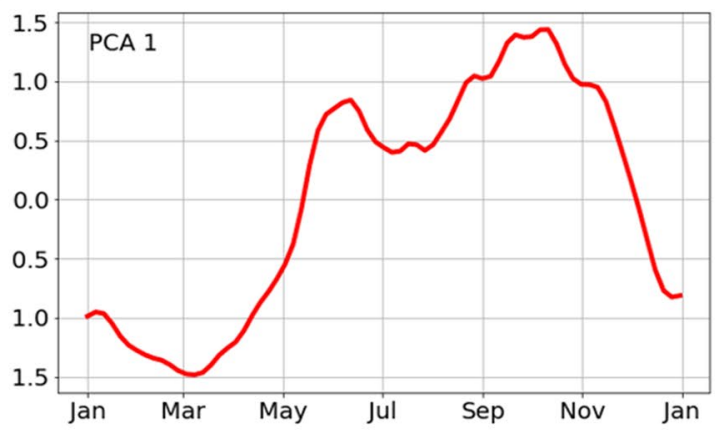

(b)

(c)
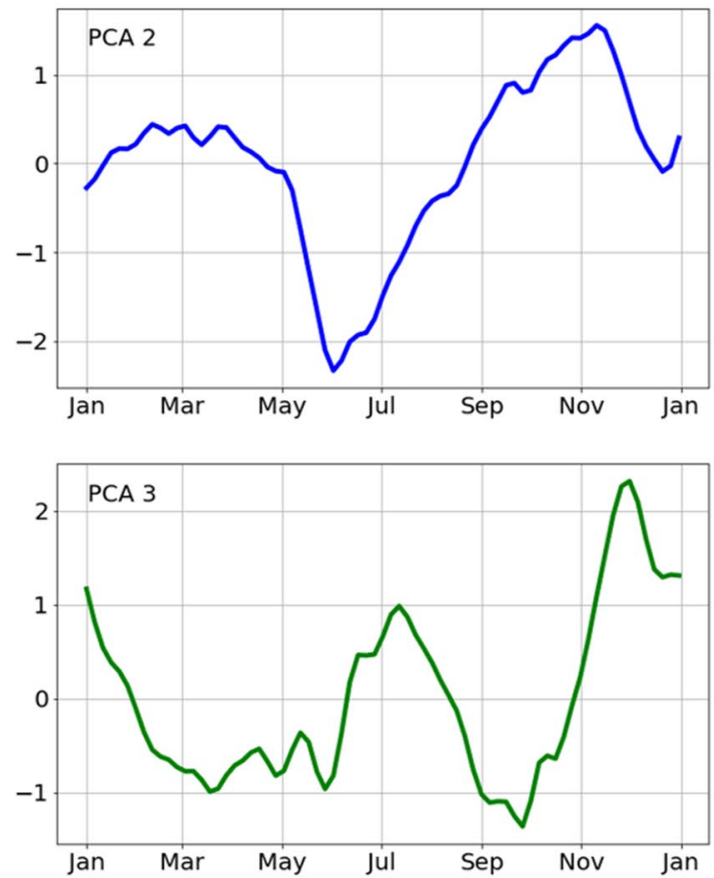

(d)

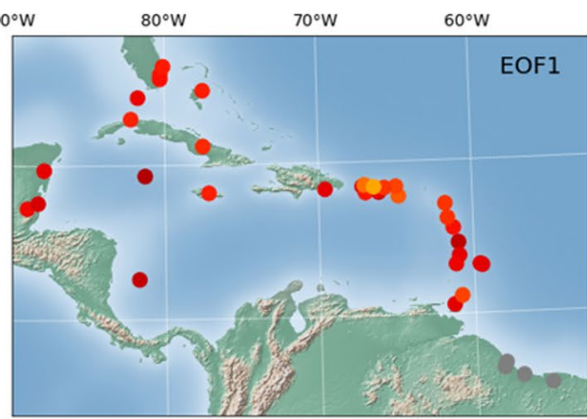

EOF1

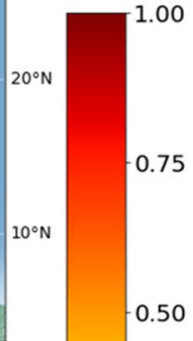

(e)
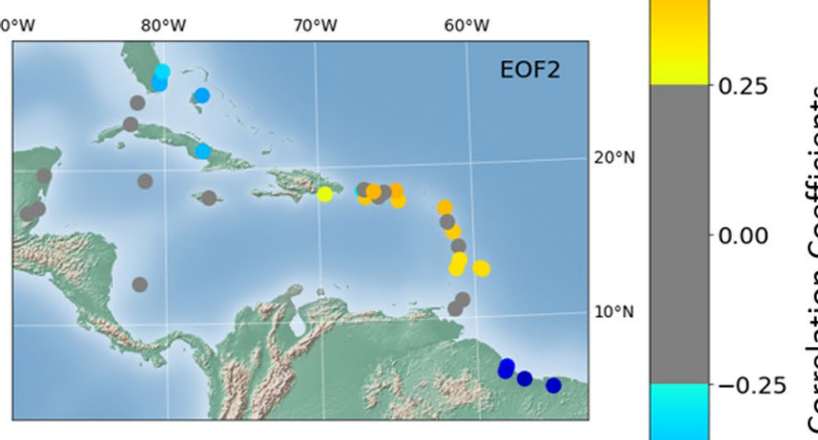

(f)

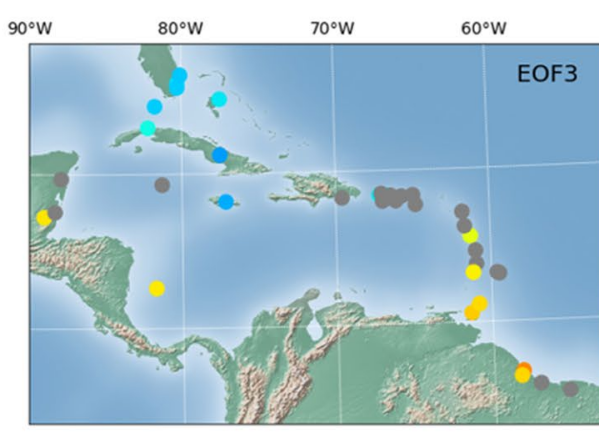

Fig. 1 Principal Component Analysis (a-c) and spatial correlation coefficients (d-f) of the climatological Caribbean pentad rainfall at 38 CIMH/ GHCN stations. Coefficients $>0.25$ or $<-0.25$ are colored for significance

and the MSD is not necessarily a dry season but rather a period of less intense rainfall than the ERS and LRS. Nearly all stations in the Caribbean have high positive correlation coefficients with PC1 (Fig. 1d; Table 2), with the exception of the four Guiana stations.

With its negative peak in June and positive peak in November, PC2 indicates a modification of the intensity of the ERS compared to the LRS rainfall (Fig. 1b). PC2 also shows a gradual ascent of rainfall towards the LRS in positively correlated stations. A notable contrast in spatial correlation pattern (Fig. 1e; Table 2) is seen with PC2 from NW to the SE portion of the Caribbean stations. Stations in the southeast, from the mid to upper portion of the Lesser Antilles, the U.S. Virgin Islands, and some in Puerto Rico have positive correlations with $\mathrm{PC} 2$, while stations in Florida, Cuba, and the Bahamas have negative correlations. This implies that the ERS peaking in June has a stronger signature in the NW Caribbean than in the SE Caribbean while the opposite is seen during the climatological LRS. Meanwhile, stations in the Guianas have high negative correlation coefficients, indicating a complete inverse of PC2: a dominant ERS and little to no rainfall during the climatological LRS. Finally, PC3 denotes, in stations positively correlated with it, the absence of the MSD and a late-LRS peaking in late November and extending into the WDS (Fig. 1c). The correlation coefficients in PC3 show a notable meridional contrast (Fig. 1f; Table 2). Stations in the NW Caribbean (i.e. Cuba, Jamaica, Bahamas, and Florida) have negative correlations whereas some stations in Central America, the lower tier of the Lesser Antilles, and Guyana, have positive correlations. Given the negative correlations seen in PC2 in the NW Caribbean, and a later peak of the LRS seen in PC3, the negative correlations in PC3 in the NW Caribbean suggest this region has a stronger signature of the MSD and an earlier 
Table 2 Correlation coefficients between the station annual cycle of rainfall and PC1, 2, and 3

\begin{tabular}{|c|c|c|c|c|}
\hline Region & (ID) Station Name & $r \mathrm{PC} 1$ & $r \mathrm{PC} 2$ & $r \mathrm{PC} 3$ \\
\hline \multirow[t]{9}{*}{ Northwest Caribbean } & (2) Nassau, Bahamas & 0.751 & -0.432 & -0.290 \\
\hline & (7) Georgetown, Cayman & 0.910 & 0.025 & -0.127 \\
\hline & (8) Camaguey, Cuba & 0.728 & -0.387 & -0.440 \\
\hline & (9) La Habana, Cuba & 0.746 & -0.214 & -0.254 \\
\hline & (15) Worthy Park, Jamaica & 0.752 & -0.029 & -0.410 \\
\hline & (23) Ft. Lauderdale, USA & 0.770 & -0.418 & -0.314 \\
\hline & (24) Key West, USA & 0.811 & -0.130 & -0.347 \\
\hline & (25) Miami Intl. AP., USA & 0.784 & -0.402 & -0.348 \\
\hline & (26) Palm Beach, USA & 0.763 & -0.321 & -0.352 \\
\hline \multirow[t]{4}{*}{ Western Caribbean } & (5) CFarm, Belize & 0.799 & -0.103 & 0.330 \\
\hline & (6) Intl. AP., Belize & 0.850 & -0.021 & 0.162 \\
\hline & (37) San Andreas, Columbia & 0.879 & -0.080 & 0.327 \\
\hline & (38) Felipe, Mexico & 0.817 & -0.111 & -0.164 \\
\hline \multirow[t]{12}{*}{ Central Caribbean/Northern Lesser Antilles } & (1) BC Bird Intl. AP., Antigua/Barbuda & 0.703 & 0.420 & 0.093 \\
\hline & (11) Santo Domingo, DR & 0.822 & 0.262 & -0.216 \\
\hline & (27) Henry E. Rohlsen AP., St. Croix & 0.628 & 0.385 & 0.166 \\
\hline & (28) Cyril E. King, St. Thomas & 0.673 & 0.444 & 0.047 \\
\hline & (29) Coloso, USPR & 0.830 & -0.275 & -0.287 \\
\hline & (30) Dora Bora, USPR & 0.641 & 0.140 & -0.318 \\
\hline & (31) Ensenda, USPR & 0.766 & 0.394 & -0.175 \\
\hline & (32) Guaynama, USPR & 0.873 & 0.026 & -0.101 \\
\hline & (33) Jajome Alto, USPR & 0.812 & 0.224 & 0.070 \\
\hline & (34) Mora Camp, USPR & 0.584 & -0.123 & -0.094 \\
\hline & (35) Paraiso, USPR & 0.708 & 0.197 & 0.116 \\
\hline & (36) Morovis N., USPR & 0.463 & 0.431 & -0.086 \\
\hline \multirow[t]{7}{*}{ Central and Southern Lesser Antilles } & (3) $\mathrm{CIMH}$, Barbados & 0.820 & 0.345 & 0.160 \\
\hline & (4) Grantley A. Intl. AP., Barbados & 0.826 & 0.346 & 0.225 \\
\hline & (10) DCAP, Dominica & 0.781 & 0.384 & 0.251 \\
\hline & (12) Guadeloupe & 0.716 & 0.131 & -0.029 \\
\hline & (16) Intl. AP., Martinique & 0.884 & 0.245 & 0.215 \\
\hline & (17) Hewanorra, St. Lucia & 0.822 & 0.334 & 0.165 \\
\hline & (18) Dumbarton, St. Vincent & 0.811 & 0.340 & 0.312 \\
\hline \multirow[t]{6}{*}{$\mathrm{T} \& \mathrm{~T} /$ Guianas } & (13) Georgetown, Guyana & 0.078 & -0.780 & 0.530 \\
\hline & (14) Time HRI, Guyana & 0.185 & -0.843 & 0.362 \\
\hline & (19) Corantjinpolder, Suriname & -0.001 & -0.895 & 0.194 \\
\hline & (20) Zanderji, Suriname & -0.067 & -0.881 & 0.064 \\
\hline & (21) Piarco, T\&T & 0.824 & -0.193 & 0.389 \\
\hline & (22) Crown Pt. T\&T & 0.676 & -0.204 & 0.356 \\
\hline
\end{tabular}

Values bolded and italicized denote significance at the 95th confidence level

LRS in comparison to the eastern Caribbean. Meanwhile, the positive correlations in Guyana is a combination of the absence of the climatological MSD and a late-LRS given their inverted relationship seen in PC2.

Overall, the PCA suggests three distinct sub-regions of the rainfall cycle in the Caribbean: the NW Caribbean, the Central and Eastern Caribbean (Puerto Rico and the Lesser Antilles), and the Guianas. However, this rough division of the Caribbean regions paints an incomplete picture. Findings from total moisture budget provide important insights on the regional precipitation patterns across the Caribbean.

\subsection{Moisture budget seasonal cycle}

The reanalysis' spatial moisture budget climatology (1979-2012) for the Caribbean is divided into the four climatological precipitation seasons: the WDS (Fig. 2), ERS (Fig. 3), MSD (Fig. 4), and LRS (Fig. 5). 


$$
\bar{P}-\bar{E}
$$

(a)

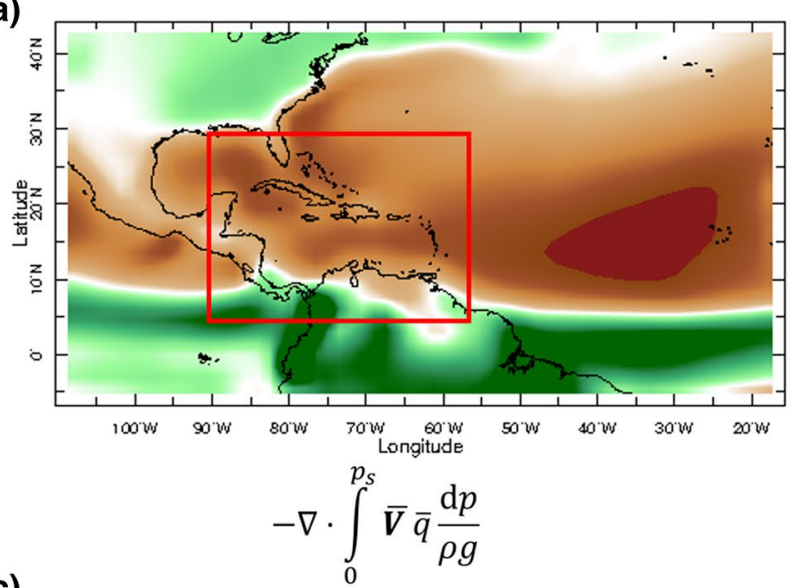

(c)

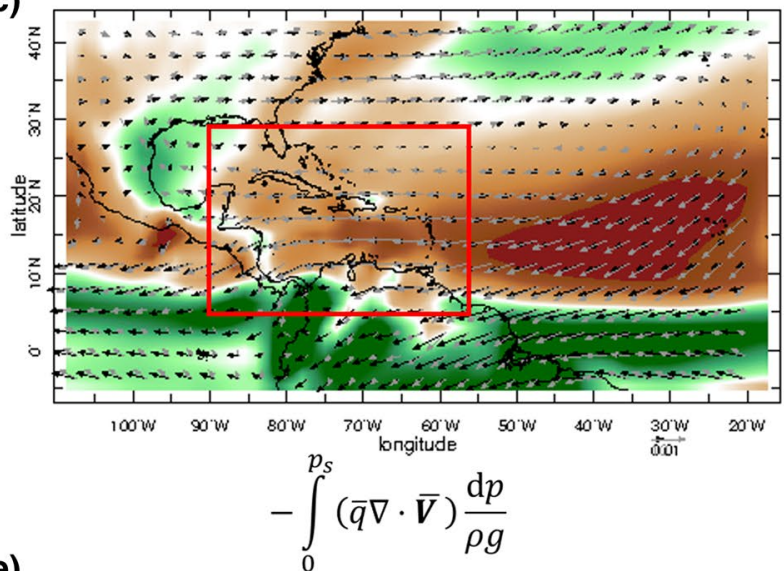

(e)

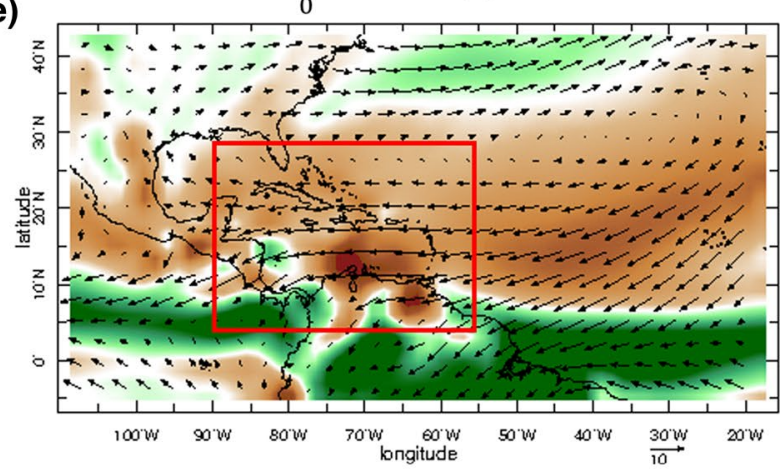

(b)

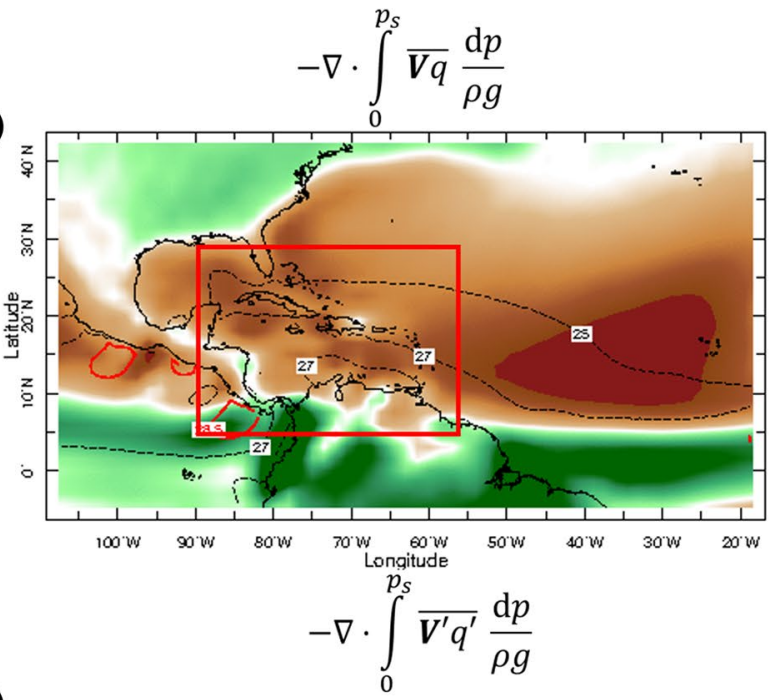

(d)

(f)

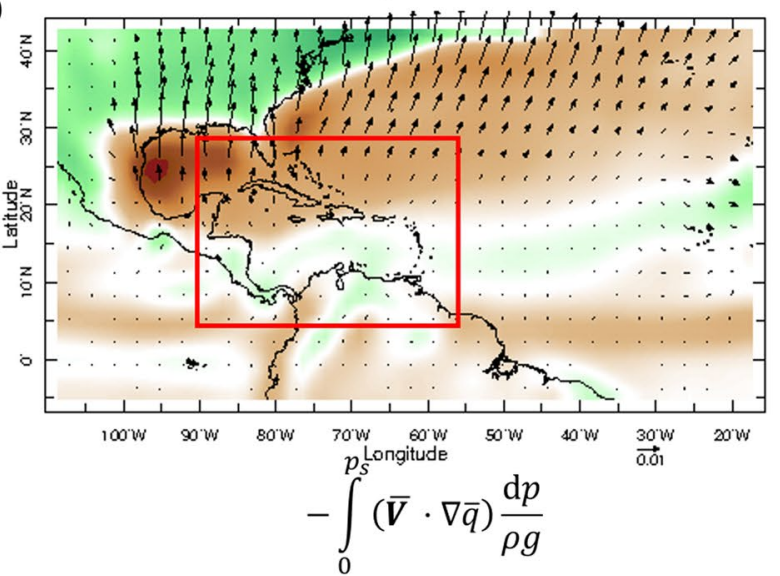

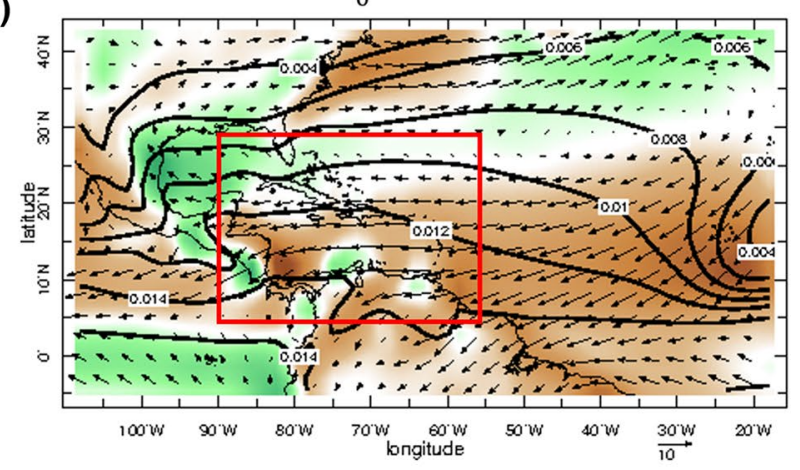

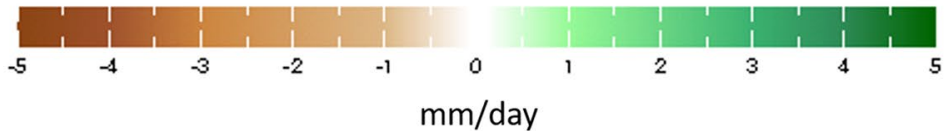

Fig. 2 Winter Dry Season (Dec-Apr) climatological seasonal mean moisture budget in $\mathrm{mm} /$ day. a Precipitation minus evaporation. Shaded in green (convergence) and brown (divergence) are b total moisture flux, $\mathbf{c}$ convergence by the mean flow, $\mathbf{d}$ convergence by the transient flow, e mass convergence, and (f) advection of specific humidity. The contours in $\mathbf{b}$ are SSTs. The black vectors in $\mathbf{c}$ and d are the vertically integrated mean and transient moisture transport vectors, respectively. The grey vectors in $\mathbf{c}$ are the $925 \mathrm{mb}$ wind vectors. The black vectors in $\mathbf{e}$ and $\mathbf{f}$ are the $925 \mathrm{mb}$ wind vectors. The solid black contours in $\mathbf{f}$ are specific humidity at $925 \mathrm{mb}$ 
(a)

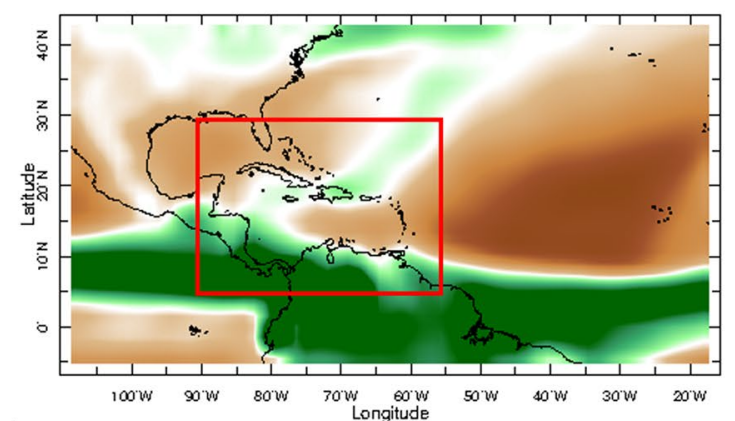

(c)

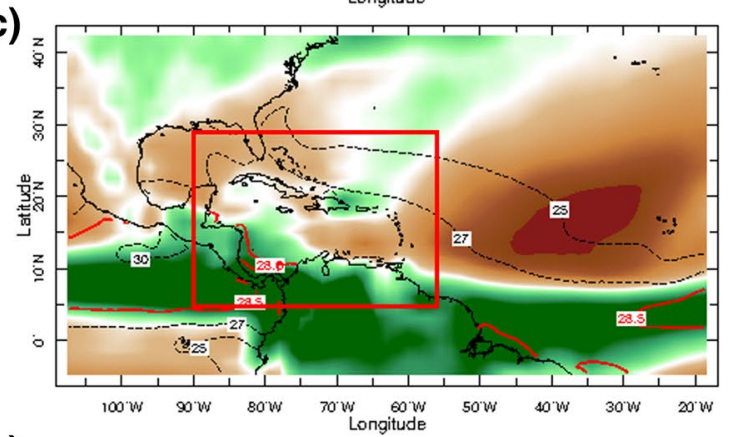

(e)

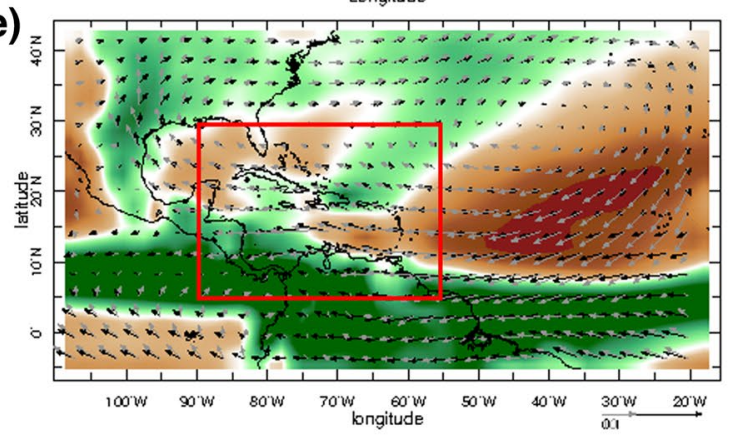

(b)

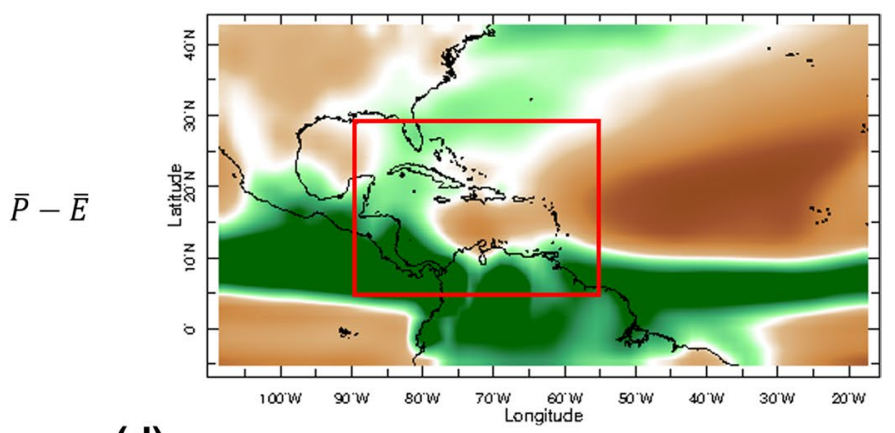

(d)

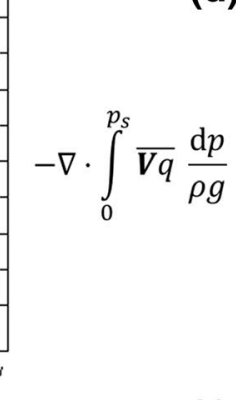

(f)

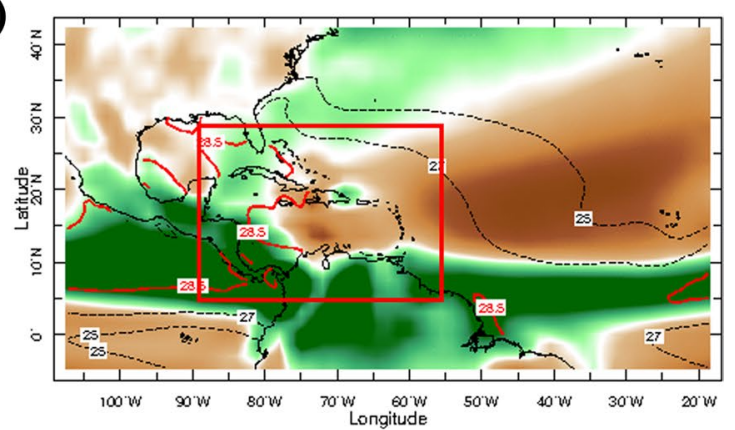

(f)

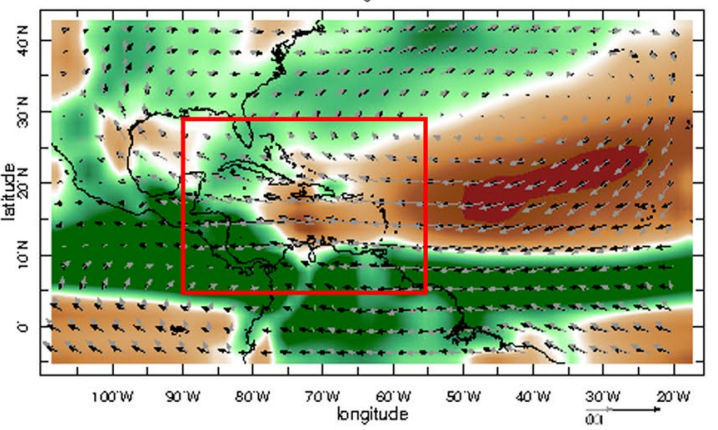

$-\nabla \cdot \int_{0}^{p_{s}} \bar{V} \bar{q} \frac{\mathrm{d} p}{\rho g}$

Fig. 3 Early Rainy Season (May-Jun) climatological monthly mean moisture budget for May (a, c, e, g, i) and June (b, d, f, h, j). a, b Precipitation minus evaporation. Shaded in green (convergence) and brown (divergence) are $\mathbf{c}, \mathbf{d}$ total moisture flux, $\mathbf{e}, \mathbf{f}$ convergence by the mean flow, $(\mathbf{g}, \mathbf{h})$ mass convergence, and $(\mathbf{i}, \mathbf{j})$ advection of spe-

\subsubsection{Winter dry season (December-April)}

Given P-E (Fig. 2a) equals the TMF (Fig. 2b) in the moisture budget equation, both terms resemble each other well in the WDS. In the TMF, convergence is found over the continental United States and south of the Caribbean domain (except Guianas) where the ITCZ is situated. Divergence is seen throughout nearly all of the Caribbean, and the tropical North Atlantic coinciding with NASH. In addition, SSTs in the Caribbean have values between 24 and $27^{\circ} \mathrm{C}$ (Fig. 2b). When the convergence of the TMF is broken down into its mean (Fig. 2c) and transient (Fig. 2d) components, the latter is seen to dominate the TMF convergence north of $20 \mathrm{~N}$, and the mean flow dominates the TMF south of $20 \mathrm{~N}$. Therefore, the convergence band in the continental U.S. and divergence cific humidity. The contours in $\mathbf{c}$ and $\mathbf{d}$ are SSTs. The black vectors in $\mathbf{e}$ and $\mathbf{f}$ are the vertically integrated mean moisture transport vectors. The grey vectors in e and $\mathbf{f}$ are the $925 \mathrm{mb}$ wind vectors. The black vectors in $\mathbf{g}-\mathbf{j}$ are the $925 \mathrm{mb}$ wind vectors. The solid black contours in $\mathbf{i}$ and $\mathbf{j}$ are specific humidity at $925 \mathrm{mb}$

band in the Gulf of Mexico and NW Caribbean are due primarily to the transient flow. The divergence across the tropical north Atlantic, SE Caribbean, and convergence bands in the Guianas/ITCZ regions are due to the mean flow. As for the transient flow, the transient mean moisture transport vectors are meridional, that is the land-ocean convergence and divergence couplet are a result of high-frequency transient eddies that transport moisture poleward.

The breakdown of the mean flow into its mass convergence (Fig. 2e) and moisture advection components (Fig. 2f) show that mass convergence is the dominant term of the mean flow impact on the moisture budget while moisture advection acts as a modifier. For instance, mean flow divergence in the tropical North Atlantic is due to mass divergence by northeasterly winds carrying lower values 

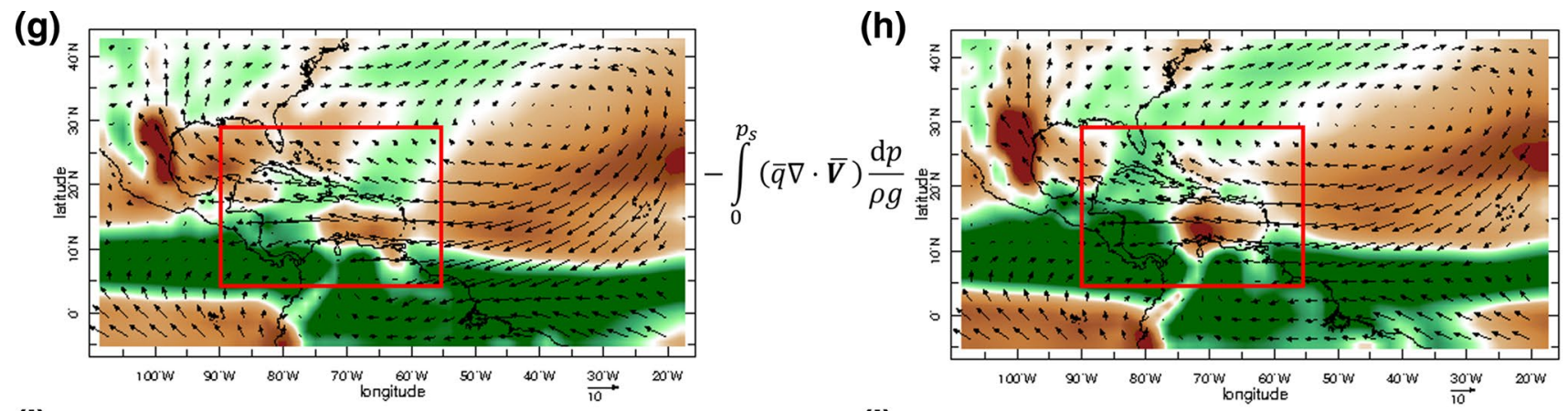

(i)
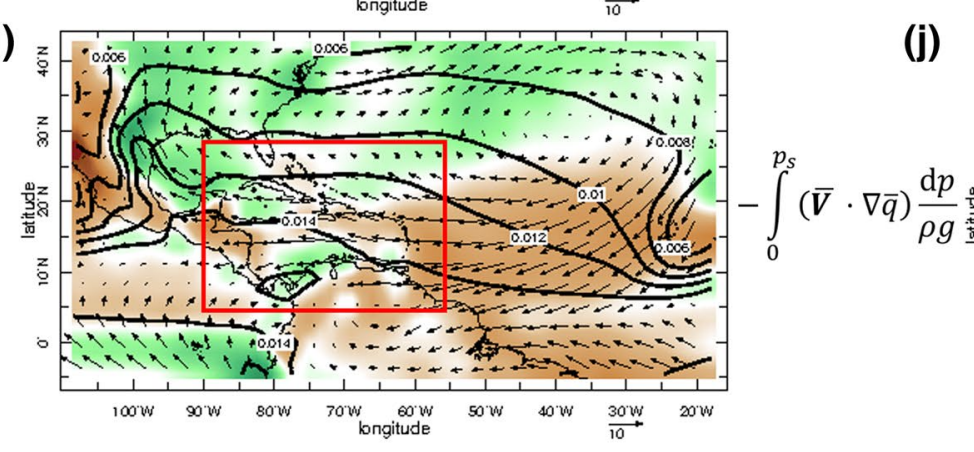

(j)
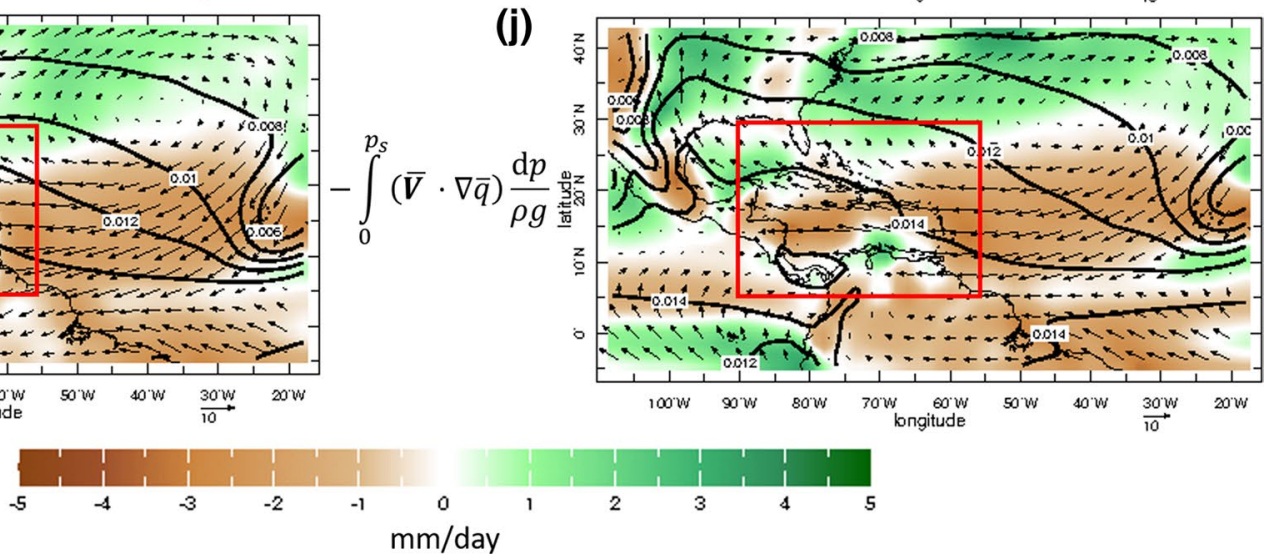

Fig. 3 (continued)

of specific humidity (q) into the region. This is as associated with the circulation imposed by the NASH along its southern flank. In addition, strong $925 \mathrm{mb}$ easterly winds are seen across the central CS, these are associated with the wintertime CLLJ (Wang 2007). The Gulf of Mexico is the only region where moisture advection dominates by acting to overcome the effect of weak mean mass divergence. Here, strong moisture advection by southeasterly winds carries higher q from the CS into the Gulf of Mexico.

\subsubsection{Early rainy season (May-June)}

During the ERS, the mean flow (Fig. 3e, f) is the dominant contributor of the TMF (Fig. 3c, d). In May, two bands of convergence in the Caribbean appear in the TMF (Fig. 3c): one in the western flank of NASH from the Dominican Republic/Puerto Rico to the mid-latitudes, and the other across western portion of the CS. Convergence also appears in the Guianas as the Atlantic ITCZ convergence band moved northward. Convergence is also seen where the northward migrating Eastern Pacific ITCZ and SAMS are located. Three zones of divergence are found: one in the Gulf of Mexico and NW Caribbean, the southern flank of $\mathrm{NASH}$, and a divergence tongue from the Lesser Antilles to the Central CS. SSTs in the CS are between $27^{\circ} \mathrm{C}-28{ }^{\circ} \mathrm{C}$ and the Gulf of Mexico is at or below $27^{\circ} \mathrm{C}$ (Fig. 3c). Areas such as the Eastern Pacific ITCZ and the Caribbean shoreline of Central America have SSTs at or above $28.5^{\circ} \mathrm{C}$, denoting the warm pool and its Caribbean branch. The regional maximum of warm waters coincides with the largest values of convergence seen in the Caribbean, which is indicative of the WHWP enhancing the Eastern Pacific ITCZ and the convection in the western $\mathrm{CS}$.

In the convergence band in the western flank of NASH, mass convergence (Fig. 3g) and advection of moister air (Fig. 3i) are found. The $925 \mathrm{mb}$ wind and mean moisture transport vectors in this convergence band have a stronger southerly component than during the WDS. Therefore, the convergence band in the western flank of NASH is a result of weakened trade winds and their associated mass divergence and higher values of $\mathrm{q}$ from the tropics being advected into the subtropics. The convergence band in the western CS is mainly associated with mass convergence that connects with the Eastern Pacific ITCZ. In addition, the $925 \mathrm{mb}$ winds in the CS have a stronger southerly component than during the WDS. Mass divergence in the central CS is weaker than during the WDS. This implies that the western CS band is receiving moisture from the Eastern Pacific ITCZ as a result of enhanced southerly flow which weakens the divergent trade winds in the CS. The Gulf of Mexico and far NW Caribbean mean flow divergence is due to mass divergence; however, positive advection of moisture via southeasterly 

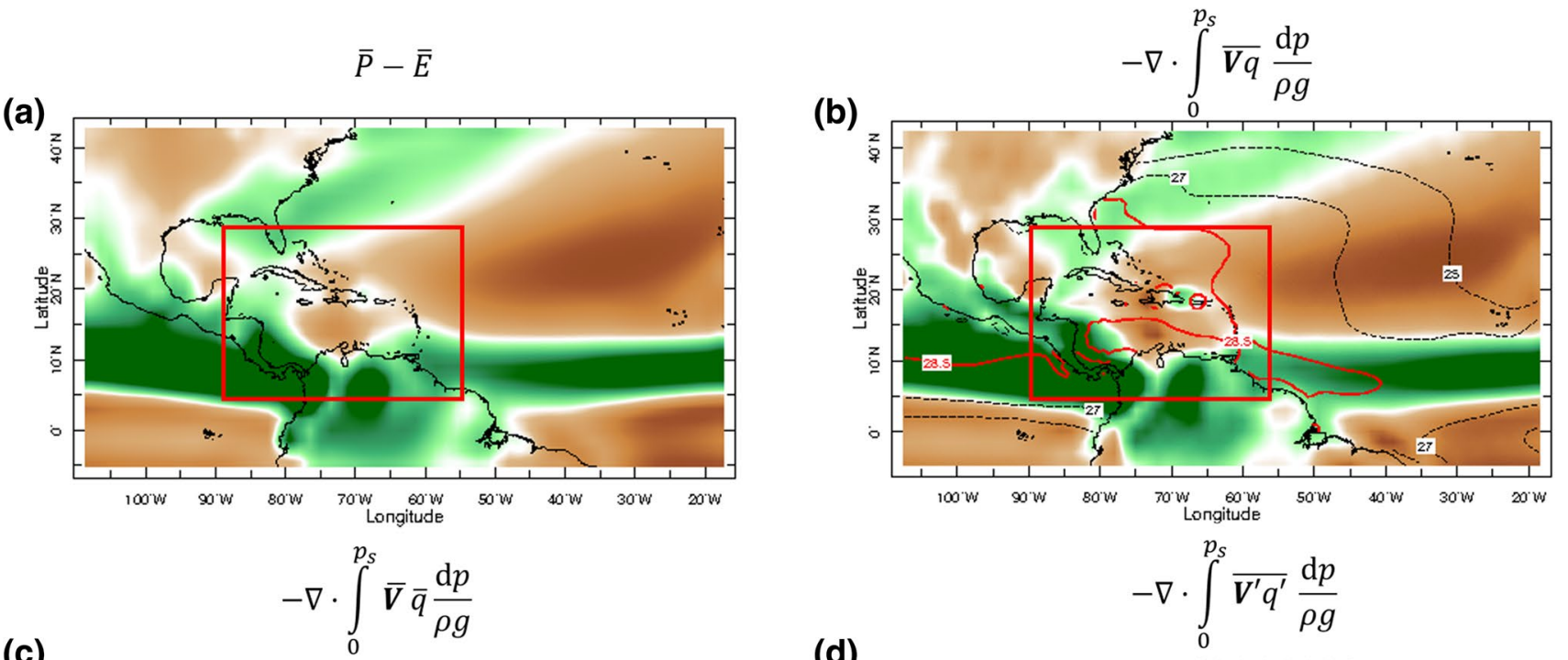

(c)

$$
-\nabla \cdot \int_{0}^{p_{s}} \overline{\boldsymbol{V}} \bar{q} \frac{\mathrm{d} p}{\rho g}
$$

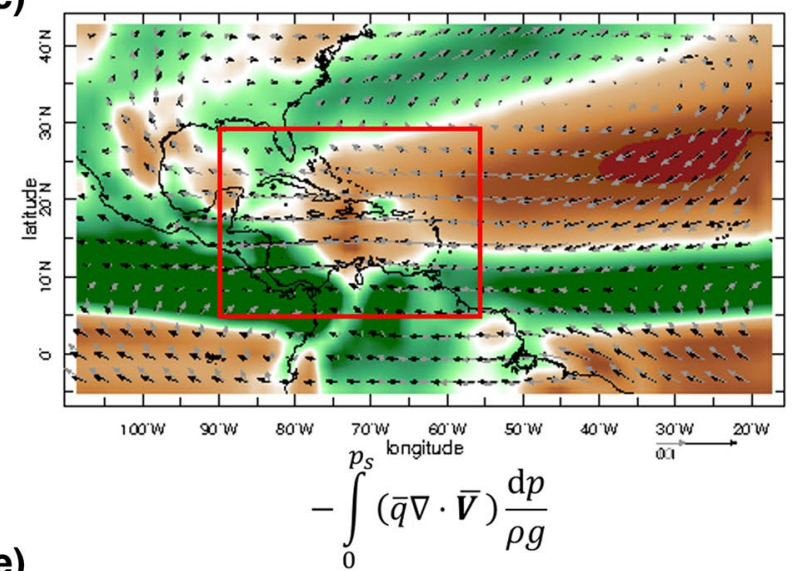

(e)

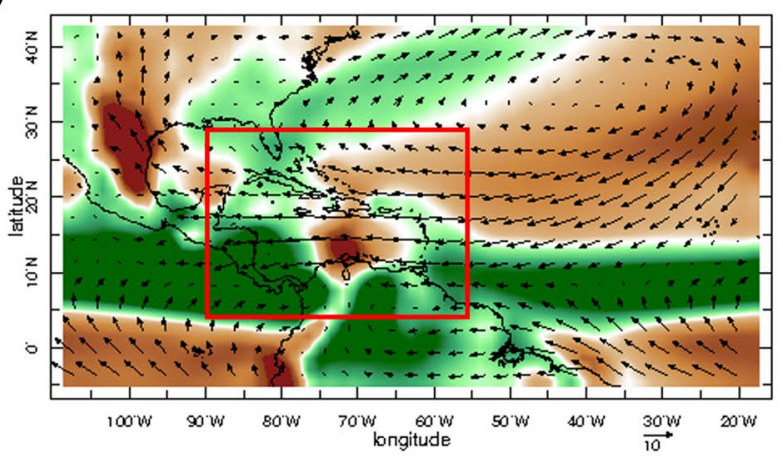

(f)
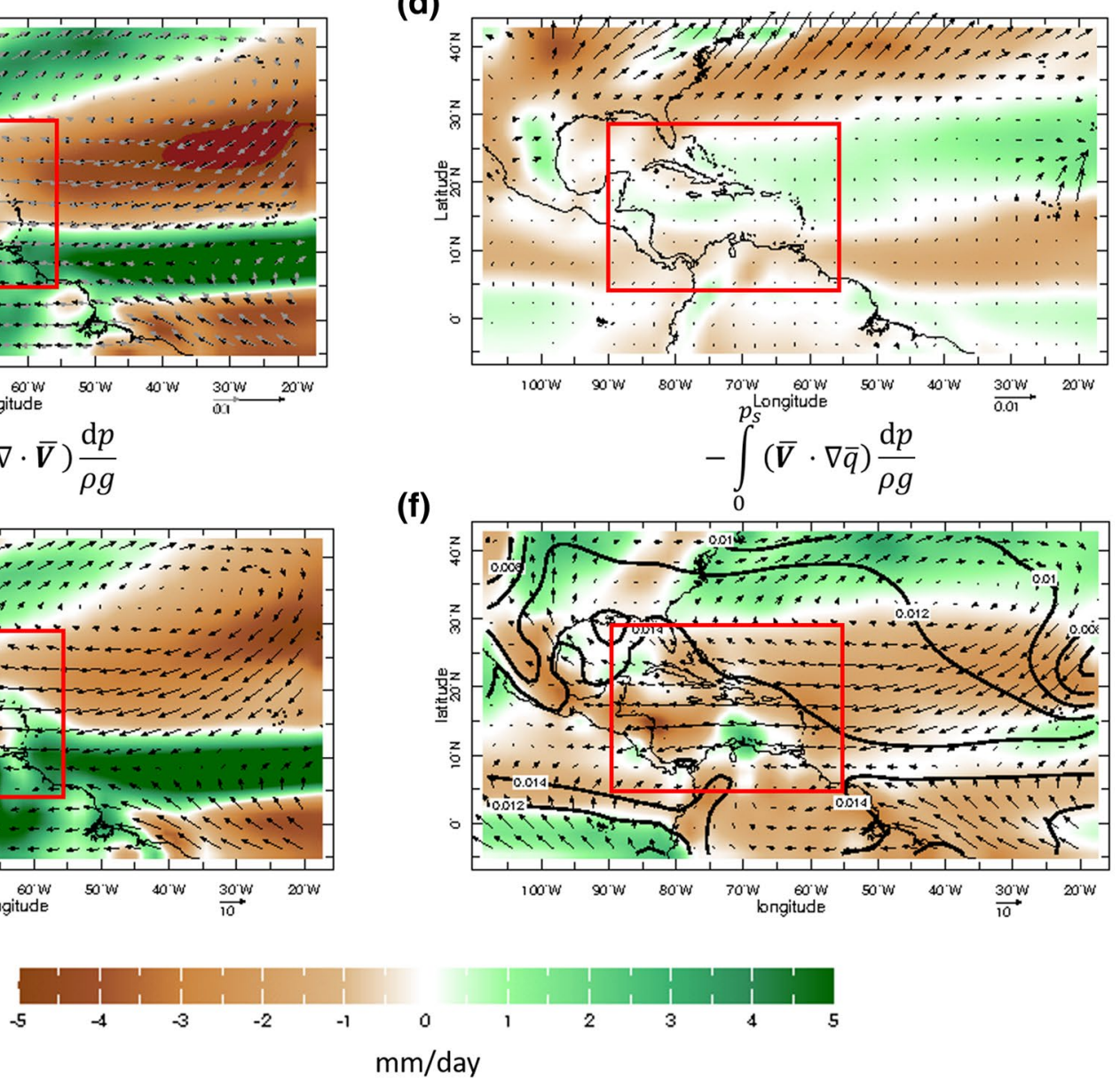

Fig. 4 Same from Fig. 2 but for the Mid-Summer Drought season (Jul-Aug)

winds in the region modifies the magnitude of the overall mean flow moisture flux divergence. Finally, the ITCZ convergent bands are a result of mass convergence by the trade winds that converge towards the ITCZ.
In June, the TMF and mean flow convergence bands associated with the western flank of NASH shifts westward to the eastern U.S. coastline and to portions of the Gulf of Mexico/NW Caribbean (Fig. 3d, f). This observation is consistent with recent studies that investigate the ERS (i.e. 

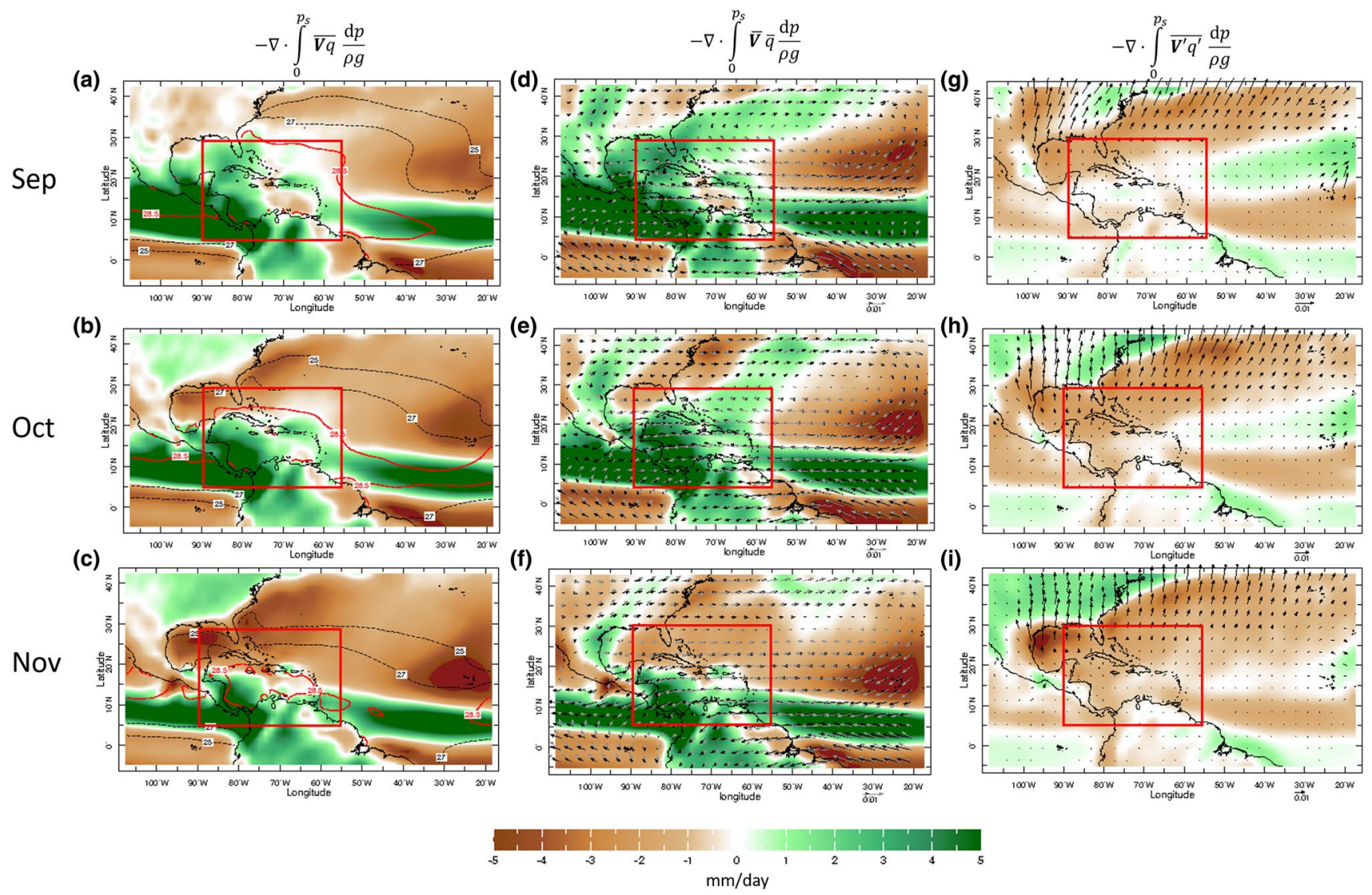

Fig. 5 Late rainy season climatological monthly mean moisture budgets for September (a, d, g), October (b, e, h), and November (c, f, i) (LRS). Shaded in green and brown are $\mathbf{a}, \mathbf{b}, \mathbf{c}$ total moisture flux, $\mathbf{d}, \mathbf{e}, \mathbf{f}$ convergence by the mean flow, and $\mathbf{g}, \mathbf{h}, \mathbf{i}$ convergence by the transient flow. The contours in $\mathbf{a}, \mathbf{b}, \mathbf{c}$ are SSTs. The black vectors in $\mathbf{d}-\mathbf{f}$ and $\mathbf{g}-\mathbf{i}$ are the integrated mean and transient moisture transport vectors, respectively. The grey vectors in $\mathbf{d}-\mathbf{f}$ are the $925 \mathrm{mb}$ wind vectors
WT5 in Moron et al. 2015; Allen and Mapes 2017). The westward shift of the western flank of NASH, mean flow convergence band is due to the westward shift of mass convergence (Fig. 3h) and northwestward shift of positive moisture advection (Fig. 3j). In addition, the $925 \mathrm{mb}$ southeasterly winds shift westward as southeasterly winds in the Gulf of Mexico and NW Caribbean have strengthened while the southeasterly winds north of the Dominican Republic/Puerto Rico have become easterly. SSTs warm throughout the Caribbean domain and the AWP $\left(28.5^{\circ} \mathrm{C}\right)$ expands to regions where convergence across the western CS and Gulf of Mexico is found (Fig. 3d). The convergence band in the western CS shifts slightly northwestward as mass convergence from the Eastern Pacific ITCZ migrated further northward. The Atlantic ITCZ convergence band is also shifts northward, but the SAMS convergence band is stagnant. For the TMF/ mean flow divergence, the divergence band in the Gulf of Mexico disappears, the divergence band in the southern flank of NASH shifts northward, and the divergence tongue in the CS extends westward as negative moisture advection (Fig. 3j) is enhanced across the CS. In addition, the $925 \mathrm{mb}$ easterly winds and mean moisture divergence vectors in the CS strengthen (Fig. 3f), similarly to what is found during the WDS. The CS mass convergence-negative moisture advection couplet found in the WDS also returns (Fig. 3h, j).

\subsubsection{Mid-summer drought (July-August)}

The MSD TMF shows three convergent bands and one large divergent band in the Caribbean domain (Fig. 4b). The convergence bands coincide where precipitation exceeds evaporation the most (Fig. 4a) and vice versa with the seen divergence bands. The first convergence band is associated with the northwestern flank of NASH and is seen from Florida to the mid-latitude Atlantic Ocean. The second convergence band is seen in the western CS, south of the Eastern Pacific ITCZ convergence band. The third convergence band is seen in the Lesser Antilles in association with the Atlantic ITCZ. The divergence band is seen in the southern flank of NASH, portions of the Greater and Lesser Antilles, and central CS. In comparison to the ERS, the NASH convergence band shifts northwestward 
and the Eastern Pacific ITCZ/Atlantic ITCZ bands move northward. The mean flow is responsible for these convergent and divergent bands (Fig. 4c). Upon the breakdown of the mean flow into its mass convergence (Fig. 4e) and moisture advection (Fig. 4f) components, mass convergence is largely responsible for the convergence bands, whereas mass divergence and negative advection of specific humidity are largely responsible for the divergent band. The enhanced negative advection across most of the Caribbean is due to marginally lower values of $q$ across the southern flank of NASH being zonally advected into the Caribbean. Mean flow convergence in the ITCZ regions and northwestern flank of NASH are a consequence of converging winds associated with the trade winds, and converging southeasterlies on the western flank of NASH which advect lower values of $q$ into the mid-latitudes, respectively. Similarly, to the WDS and ERS-June, a large convergence-divergence couplet is seen between mass convergence and moisture advection in the CS.

The western CS alongside the Nicaragua shoreline has mass convergence and advection of drier air, whereas the central CS north of the Bay of Venezuela has mass divergence and positive moisture advection. Similar during the WDS, a pocket of lower $\mathrm{q}$ and strong divergent winds are seen north of the Bay of Venezuela, whereas larger values of $\mathrm{q}$ and strong convergent winds are seen to its east and west. The SSTs at and around the CS divergence pocket are cooler than the surrounding region (Fig. 4b), which is likely a result of coastal upwelling (Inoue et al. 2002). This upwelling is forced by the low-level easterly winds, or CLLJ, that are parallel to the South American coastline (Fig. 4c, e). In addition, the AWP (28.5C) extends eastward into the Lesser Antilles but does not reach the North South American coastline (Fig. 4b). This induces an inverted meridional SST gradient from the northern South American coast to the Greater Antilles. Based on thermal wind balance, the negative meridional temperature gradient enhances low-level winds from the east (Angeles et al. 2010; Wang 2007) in a positive feedback loop. Given that the CLLJ peaks during the MSD, it drives the moisture convergence-divergence couplet, an observation that is consistent with previous studies (Muñoz et al. 2008; Hidalgo et al. 2015; Herrera et al. 2015).

Finally, transient flow impact on the moisture budget is relatively weak across the Caribbean (Fig. 4d). That said, transient convergence modifies the extent of mean flow divergence as values of transient convergence are seen off the coast of West Africa and the Caribbean. The mean transient transport vectors over the tropical North Atlantic and off of West Africa are meridional; therefore, the transient convergence is a response to easterly moving high-frequency eddies (i.e. AEWs). However, the negligible transient convergence values seen in the Caribbean suggests their influence is marginal.

\subsubsection{Late-rainy season (September-November)}

The LRS TMF in September shows convergence throughout most of the Caribbean domain (Fig. 5a) as precipitation well exceeds evaporation (not shown). Convergence is seen throughout the NW Caribbean, eastern Central America, the Greater Antilles, and the Lesser Antilles. Some divergence is seen in the central CS and in the Guianas. The AWP covers the entire Caribbean domain (Fig. 5a). When breaking down the TMF into its mean (Fig. 5d) and transient (Fig. 5g) components, it is found that TMF convergence is due to convergence from the mean flow. Mass convergence (not shown) is the dominate component of the LRS mean flow as moisture advection (not shown) is negative but negligible across the Caribbean. In the mean flow, three bands of convergence are found: one located on the climatological Atlantic ITCZ, one located on the climatological Eastern Pacific ITCZ, and one located on the western flank of NASH. Both ITCZ convergence bands are seen in the TMF and only the southern portion of the western flank of NASH convergence band is seen in the TMF. Transient divergence is found across the Gulf of Mexico and where the northwestern flank of NASH is located. Therefore, transient divergence overtakes the mean flow convergence northeast of Florida, which results in TMF divergence. The mean transient transport vectors are mainly meridional and increasing in magnitude poleward; thus, extratropical high-frequency transient eddies are likely responsible for transient divergence seen in the Gulf of Mexico and U.S. eastern coastline.

When comparing the LRS-September to the seasonal MSD, it is found that the mean flow NASH convergence band migrates southward as the Eastern Pacific and Atlantic ITCZ convergence bands migrate northward. SAMS mean flow convergence band weakens and remains stagnant. The mean flow divergence pocket seen in the central CS is diminished. The southern flank of NASH divergence band is also diminished. Low-level winds shift from easterly to southeasterly across most of the Caribbean domain. Therefore, the migration of large-scale convergence bands alongside winds that favor mass convergence may explain the enhanced convergence across the entire Caribbean. As for transience, the convergence seen in the Caribbean and off of West Africa is diminished as divergence from the mid-latitudes extends southward into the Gulf of Mexico and portions of the NW Caribbean. This suggests mid-latitude high-frequency transient eddies extending southward as tropical easterly highfrequency transient eddies, i.e. AEWs, diminish.

In October, TMF convergence moves southward in the Caribbean (Fig. 5b) Convergence is seen across the Lesser Antilles, Central America, and Puerto Rico/Dominican 
Republic. Divergence infiltrates the NW Caribbean and Gulf of Mexico, as evaporation strengthens and exceeds precipitation (not shown) across the NW Caribbean and Gulf of Mexico. The mean flow (Fig. 5e) shows Atlantic ITCZ and Eastern Pacific ITCZ bands shifting slightly southward. The NASH mean flow convergence band shifts southeastward and is at similar position seen during the ERS-May. However, most of the NASH convergence band vanishes. Transient divergence by U.S. mainland high-frequency midlatitude eddies (Fig. 5h) shifts southward and strengthens; therefore, the transient divergence overtakes the NASH convergence band. Also, seen in the TMF is the contraction of the AWP (Fig. 5b). SSTs at or below $27{ }^{\circ} \mathrm{C}$ in the Gulf of Mexico and portions of the NW Caribbean while the rest of the Caribbean is at or above 28.5C. Notably, areas in the Caribbean that have larger mean flow convergence than transient divergence, have SSTs at or greater than $28.5^{\circ} \mathrm{C}$, whereas the opposite is true where transient divergence is greater. Finally, low-level winds remain southeasterly across the eastern half of the Caribbean domain, whereas the western half sees an easterly shift. The easterly shift in the western half of the Caribbean is also on the southern flank of an emerging anticyclonic feature seen in the SE United States, which is likely the continental High.

TMF convergence zone moves further southward in November (Fig. 5c) as evaporation strengthens (not shown) and precipitation weakens (not shown) across most of the Caribbean. Convergence is seen across the Caribbean coast of Central America and the southern half of the Lesser Antilles in correspondence to the southward shift of the Atlantic ITCZ and Eastern Pacific ITCZ convergence bands (Fig. 5f). The Atlantic ITCZ shift results in moisture convergence to return to the Guianas. SAMS shifts southward. A pocket of convergence is seen in Dominican Republic/ Puerto Rico and is a result of enhanced surface term convergence on top of mass convergence (not shown). The Caribbean is now under the influence of the southern flank of a broad anticyclonic circulation consisting of NASH and the continental U.S. anticyclone. The shift of low-level winds to easterly across the entire Caribbean is likely responsible for the pocket of convergence via orographic lifting/zonal convergence across the Caribbean side of Central America. The mean flow NASH convergence band disappears and is replaced by mean flow divergence. Mean flow divergence is also seen in the NW Caribbean and Gulf of Mexico. Therefore, mean flow divergence enhances TMF divergence in the Gulf of Mexico and NW Caribbean that is dominated by transient divergence (Fig. 5i). SSTs continue to cool across the Caribbean (Fig. 5c) and the AWP contracts further and is concentrated in the CS.

\subsection{Caribbean climate regions and pentad climatologies}

Based on the findings from the PCA, three sub-regions are seen in the Caribbean. However, with the results of the moisture budget analysis, five distinct regions are found, each with unique rainfall cycle characteristics (Fig. 6): Central Caribbean (Region 1: Dominican Republic, Puerto Rico, the Virgin Islands, and Northern Lesser Antilles), the Western Caribbean (Region 2: Caribbean coast of Central America), the Northwest Caribbean (Region 3: Florida, Bahamas, Cuba, Cayman Islands, and Jamaica), the Central and Southern Lesser Antilles (Region 4), and Trinidad \& Tobago (T\&T) / Guianas (Region 5). Furthermore, the TRMM-based results support the multi-seasonality of the different regions based on the station data (Fig. 7). Although most of the regional pentad climatologies in TRMM have lower magnitudes than the station data, this is possibly due to TRMM containing some ocean grids in its pentad calculations. Another possible source of difference could be due to the different temporal coverage of the station vs. TRMM data as shown in Fig. 7. However, when the station data temporal range matches with TRMM the station pentad climatologies' from 1969 to 2017 vs. 1998-2014 matched well; therefore, there are no systematic differences between the two different sets of climatological periods. In sum, the station dataset is robust to represent the regional climatology.

\subsubsection{Central Caribbean}

The Central Caribbean rainfall cycle is influenced by moisture convergence associated with the expansion and contraction of the western flank of the NASH. At the beginning of the ERS (late-April/early May) convergence from the western flank of NASH emerges anywhere from the northern Lesser Antilles to Puerto Rico, and progresses northwestward into the NW Caribbean as NASH expands westward. The pentad climatologies (Fig. 7a, b) show an ERS in the Northern Lesser Antilles, and its magnitude increases over the U.S. Virgin Islands and Puerto Rico. However, their ERS peaks in May and diminishes in June, hence, the positive correlations seen in PC2 (absence of ERS in June) in this region. Moisture divergence from the southern flank of NASH returns in the Central Caribbean, which causes the MSD. During the LRS, NASH contracts eastward and its western flank moves back into the Central Caribbean on a similar path to what is seen during the ERS. The western flank stalls and dissipates in the Central Caribbean as NASH merges with the continental U.S. High; therefore, convergence remains in the region and is why the Central Caribbean LRS has a longer duration than its ERS (Fig. 7a, b). 


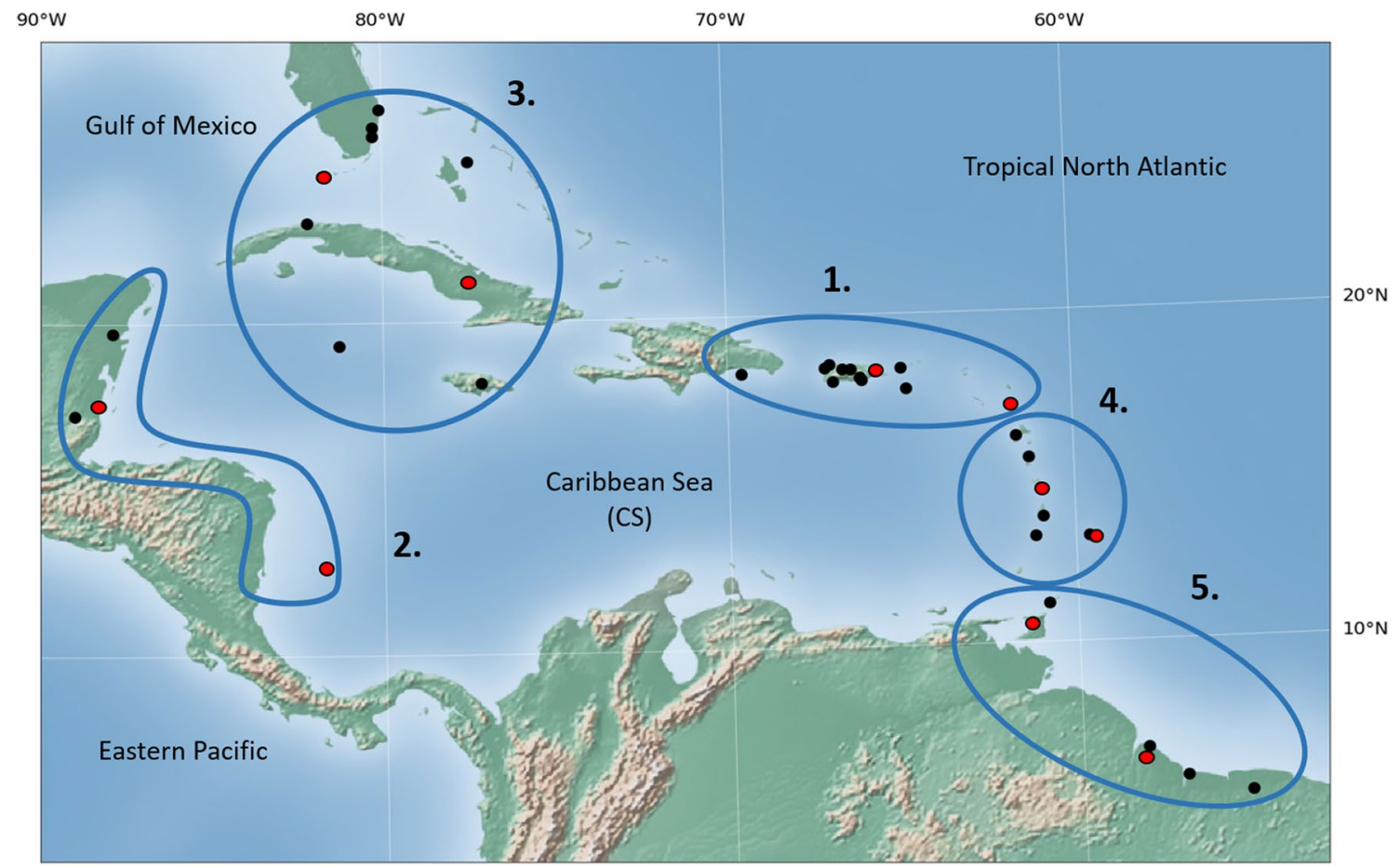

Fig. 6 Regional Classifications for the Caribbean. (1) Central Caribbean; (2) Western Caribbean; (3) Northwest Caribbean; (4) Central and Southern Lesser Antilles; (5) Trinidad and Tobago (T\&T) and Guianas. Red dots indicate stations shown in Fig. 7

\subsubsection{Western Caribbean}

The Western Caribbean rainfall cycle is dominated by the Eastern Pacific ITCZ with some interactions between ITCZ and NASH and regional modifications by the AWP and the CLLJ. The ERS peaks later than the Central Caribbean, starting in late May through early July (Fig. 7c, d). The northward migration of the Eastern Pacific ITCZ provides moisture for the Western Caribbean during the ERS to LRS. During the ERS, P-E is enhanced in this region from two convergence bands in the western CS: one on the Nicaraguan to Costa Rican Caribbean coast, and the other extending from Jamaica to the Yucatan/Belize Caribbean coast. Both are enhanced by the AWP; however, the former receives convergence from orographic lifting and zonal convergence by easterly winds, and the latter receives convergence from the transport of moisture from NASH induced southeasterly winds. During the MSD easterly winds are enhanced by the expansion of NASH, which (1) enhances orographic lifting and zonal convergence by the CLLJ and (2) cuts off penetration of the Eastern Pacific ITCZ into the Caribbean. Therefore, most of the Western Caribbean experiences an MSD but not to the extent seen in other regions. The pentad climatologies and PC3 support these findings. Stations in the western Caribbean (Fig. 7c, d) have a less prominent MSD and no significant correlation with PC3. The exception is the Nicaraguan to Costa Rican Caribbean coastlines where a lack of the MSD is observed due to enhanced convergence by the CLLJ (Herrera et al. 2015; Hidalgo et al. 2015). During the LRS, the easterly winds weaken as NASH contracts, and the moisture regime and processes described during the ERS return. The slow southward migrating Eastern Pacific ITCZ stays in the Western Caribbean. which is likely why the pentad climatologies and PC3 show a late-end and start to the LRS and WDS, respectively.

\subsubsection{Northwest Caribbean}

The NW Caribbean rainfall cycle is similar to the Western Caribbean, except it is influenced more by the expansion-contraction of the western flank of NASH, and migration patterns of U.S. mainland mid-latitude features. During the second half of the ERS, the convergence band associated with the western flank of NASH migrates from the Central Caribbean to the NW Caribbean. This is consistent with the negative correlation between $\mathrm{PC} 2$ and rain gauge stations on the eastern half of the NW Caribbean. In addition, the NASH southeasterly winds in the CS provide moisture to extend the Eastern Pacific ITCZ into the southern portion of the NW Caribbean. During the MSD, this ITCZ penetration is marginal as divergence associated with trade winds on the southern flank of NASH infiltrates the CS. The pentad climatologies (Fig. 7e, f) and the phase of PC3 support these findings in the moisture budget. The NW Caribbean has 
(a)

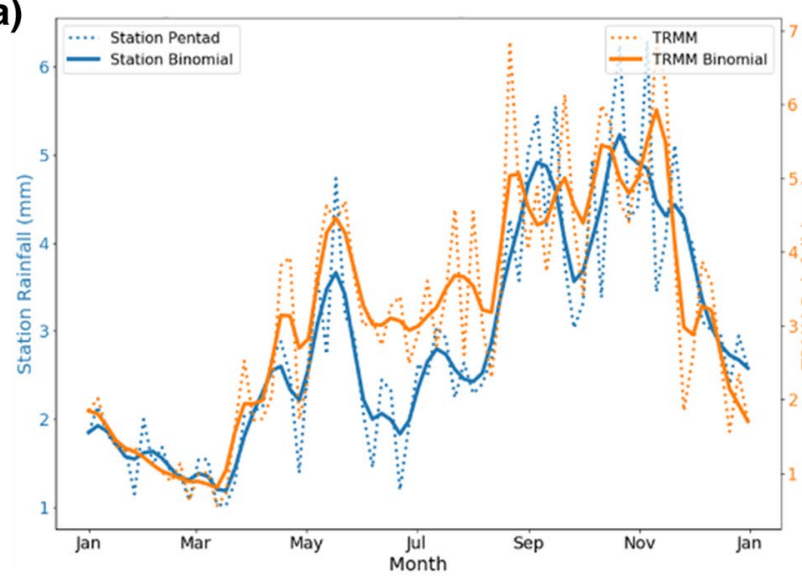

(c)

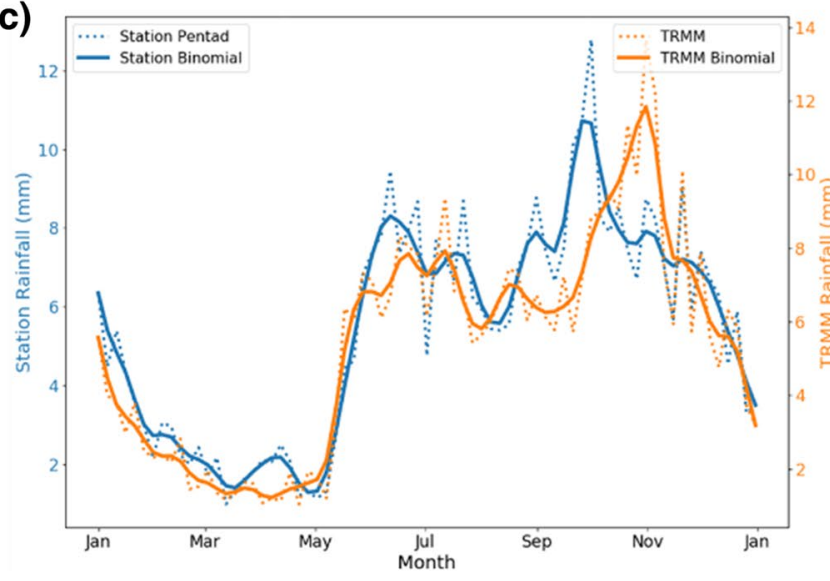

(e)

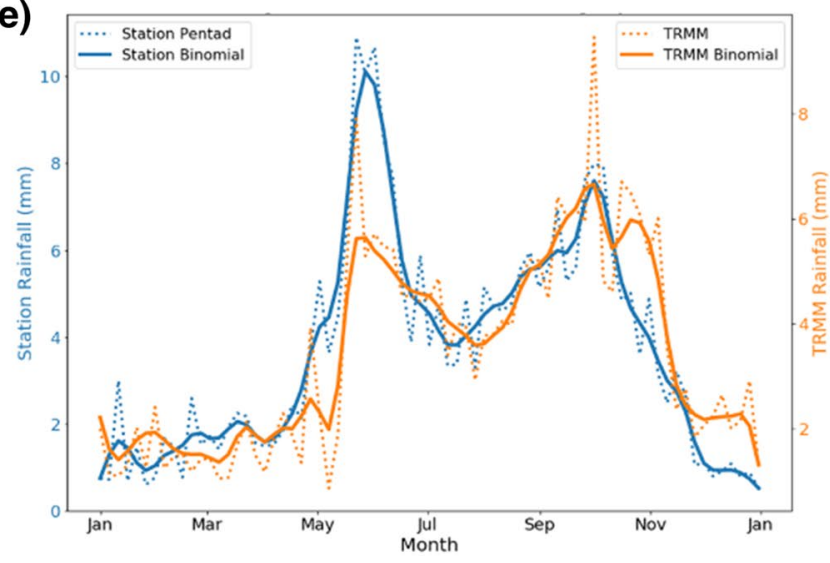

Fig. 7 Pentad rainfall climatologies in millimeters/day in the Central Caribbean: a Antigua and Barbuda, b Paraiso, Puerto Rico; the Western Caribbean: c Belize City, Belize, d San Andreas, Colombia; the Northwest Caribbean: e Camaguey, Cuba, f Key West, USA; the Central and Southern Lesser Antilles: $\mathbf{g}$ Martinique, h Grantley, Barbados; and the T\&T and Guianas: i Piarco, Trinidad and Tobago, j Time

negative correlations with PC3, which is largest in its southern half, consistent with the absence of the MSD. During the LRS, NASH contracts and its western flank moves southeast on a similar path seen during the ERS. However, transient (b)

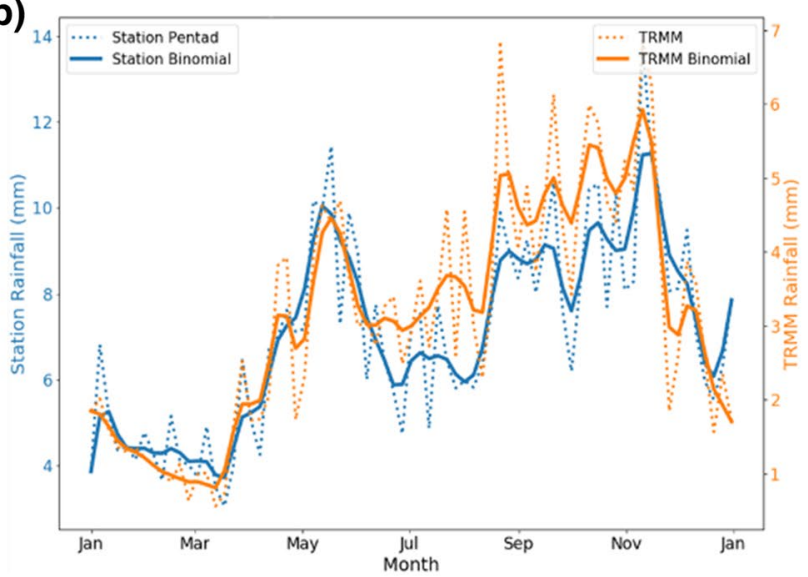

(d)

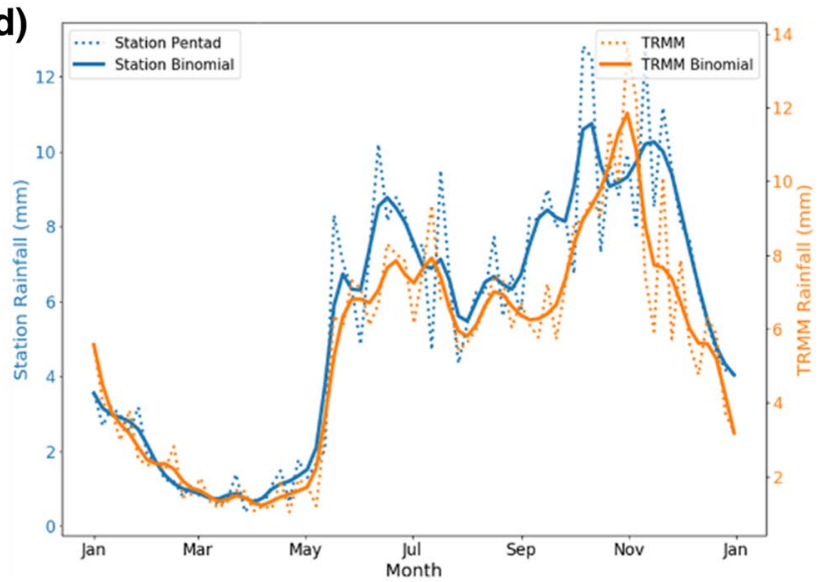

(f)

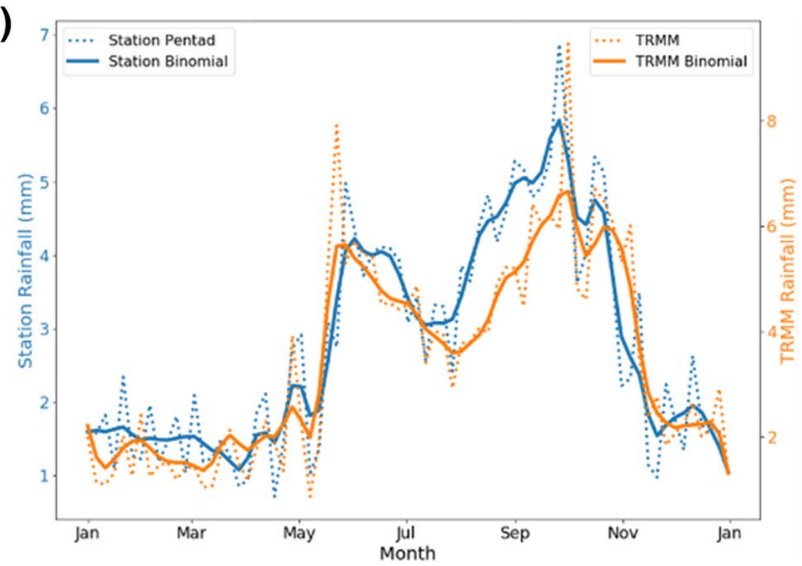

HRI, Guyana. The blue dotted and solid lines represent the pentad and binomial filtered station precipitation climatology (respectively) averaged over the specified stations for the period 1969-2017. The orange dotted and solid lines represent (respectively) the area-averaged pentad and binomial filtered TRMM precipitation climatologies in the station-based classified regions, for the period 1998-2014

divergence from U.S. mainland mid-latitude features quickly strengthens in the continental U.S. and propagates into the Gulf of Mexico and eastern Atlantic. Simultaneously, the AWP begins its contraction in the Caribbean over the NW 

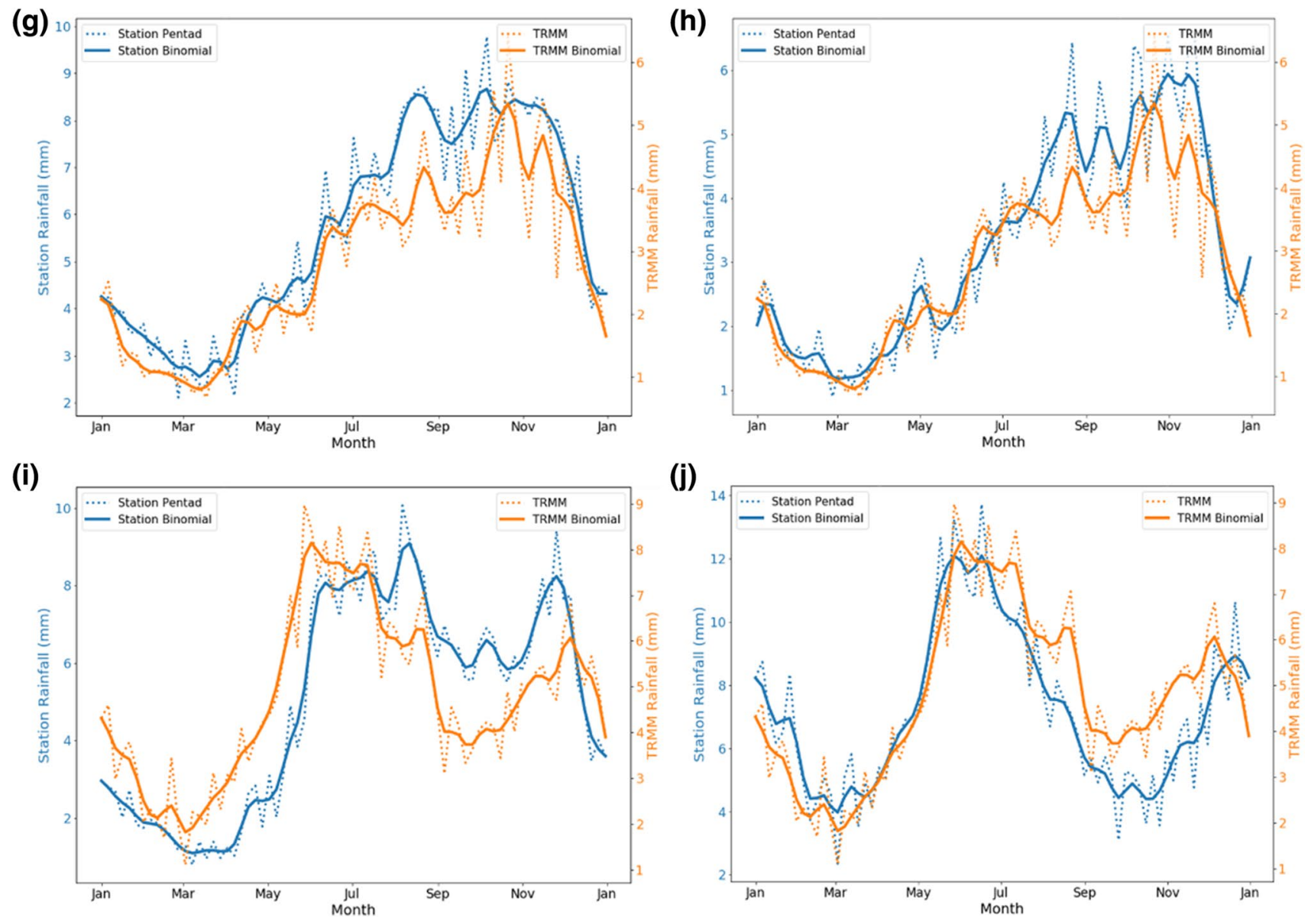

Fig. 7 (continued)

Caribbean first. Therefore, convergence from the western flank of the NASH dissipates as a result of transient divergence overtaking mean flow convergence in the NW Caribbean and the disappearance of the AWP. This supports what is seen in the pentad climatologies (Fig. 7e, f) and in PC3 in the NW Caribbean. PC3 shows that these stations have negative correlations to a late-LRS, and the pentad climatologies show these stations have the earliest demise of the LRS than any other region in the Caribbean.

\subsubsection{Central and Southern Lesser Antilles/T\&T/Guianas}

The Central and Southern Lesser Antilles and the Trinidad and Tobago (T\&T)/Guianas rainfall cycles are affected by competing influences from the Atlantic ITCZ and the diverging trade winds on the southern flank of NASH. During its northward migration, Atlantic ITCZ convergence moves through the Guianas and T\&T during the late-ERS and into MSD and slows down while reaching its northern most extent at the central Lesser Antilles by the mid LRS. While the Atlantic ITCZ migrates north from the southern to central Lesser Antilles during the MSD to mid LRS, divergence is seen across the Guianas. During the late-LRS, convergence returns in T\&T and the Guianas as the Atlantic ITCZ migrates south and divergence associated with the trade winds returns in the central and southern Lesser Antilles. The Atlantic ITCZ and its migration pattern explains what is seen in the Lesser Antilles and Guianas in the PCA analysis and pentad climatologies (Fig. $7 \mathrm{~g}-\mathrm{j}$ ). This is consistent with numerous rainfall studies in the Guianas (i.e. Shaw 1987; Bovolo et al. 2012; Durán-Quesada et al. 2012); however, no study has mentioned the Atlantic ITCZ as the major source of moisture convergence for the Lesser Antilles. The lack of an ERS seen in the Lesser Antilles (Fig. 7g, h) is in response to not only divergence by NASH (Gamble et al. 2007) and trade winds, but also due to the absence of the Atlantic ITCZ in the region during the ERS. This also explains the Guianas' negative correlations in PC1, and the positive correlations with PC3 across T\&T and Guianas. The bimodal rainfall pattern in the T\&T and Guianas (Fig. 7i, 
j) is distinct from the climatological bimodal pattern seen in most of the Caribbean.

\section{Summary and discussion}

This study analyzed the seasonal cycle of rainfall in the Caribbean using a principal component analysis (PCA) of station data from the Caribbean Institute for Climatology and Hydrology (CIMH) and NOAA Global Historical Climatological Network between 1960 and 2017. The first principal component (PC1) shows high positive correlations across the entire Caribbean as it details the well-known bimodal rainfall structure of the Caribbean: the Winter Dry Season, Early-Rainy Season, Mid-Summer Drought, and Late-Rainy Season. When the ERS and LRS are modified (PC2), a NW to SE contrast is seen where stations in the NW Caribbean show positive correlations to a strong ERS and weak LRS while stations in the Eastern Caribbean show positive correlations to a weak ERS and strong LRS. A meridional contrast for stations in PC3 is found as NW Caribbean stations show positive correlations to an enhanced MSD and early-peaking LRS, while stations in lower latitudes show positive correlations to an absent MSD and late-peaking LRS.

This study then presents a detailed total moisture budget for the Caribbean by using the ERA-Interim Reanalysis from 1979 to 2012. The results suggest three facilitators of moisture convergence that influence the seasonal cycle of rainfall in the Caribbean: the western flank of North Atlantic Subtropical High (NASH), the Eastern Pacific ITCZ, and the Atlantic ITCZ. In addition, two inhibitors of moisture are found to influence the seasonal cycle of rainfall in the Caribbean: mid-latitude transients from the continental United States, and the trade winds along the southern flank of NASH. The Atlantic Warm Pool (AWP) branch of the Western Hemispheric Warm Pool (WHWP) and Caribbean Low-Level Jet (CLLJ) act as regional modifiers of moisture convergence in the Caribbean.

The Caribbean is categorized into five climate subregions based on the findings from the PCA and moisture budget analysis: Central Caribbean, Western Caribbean, NW Caribbean, Central and Southern Lesser Antilles, and the Trinidad and Tobago and Guianas. A schematic (Fig. 8) is proposed to demonstrate the interactions of the main

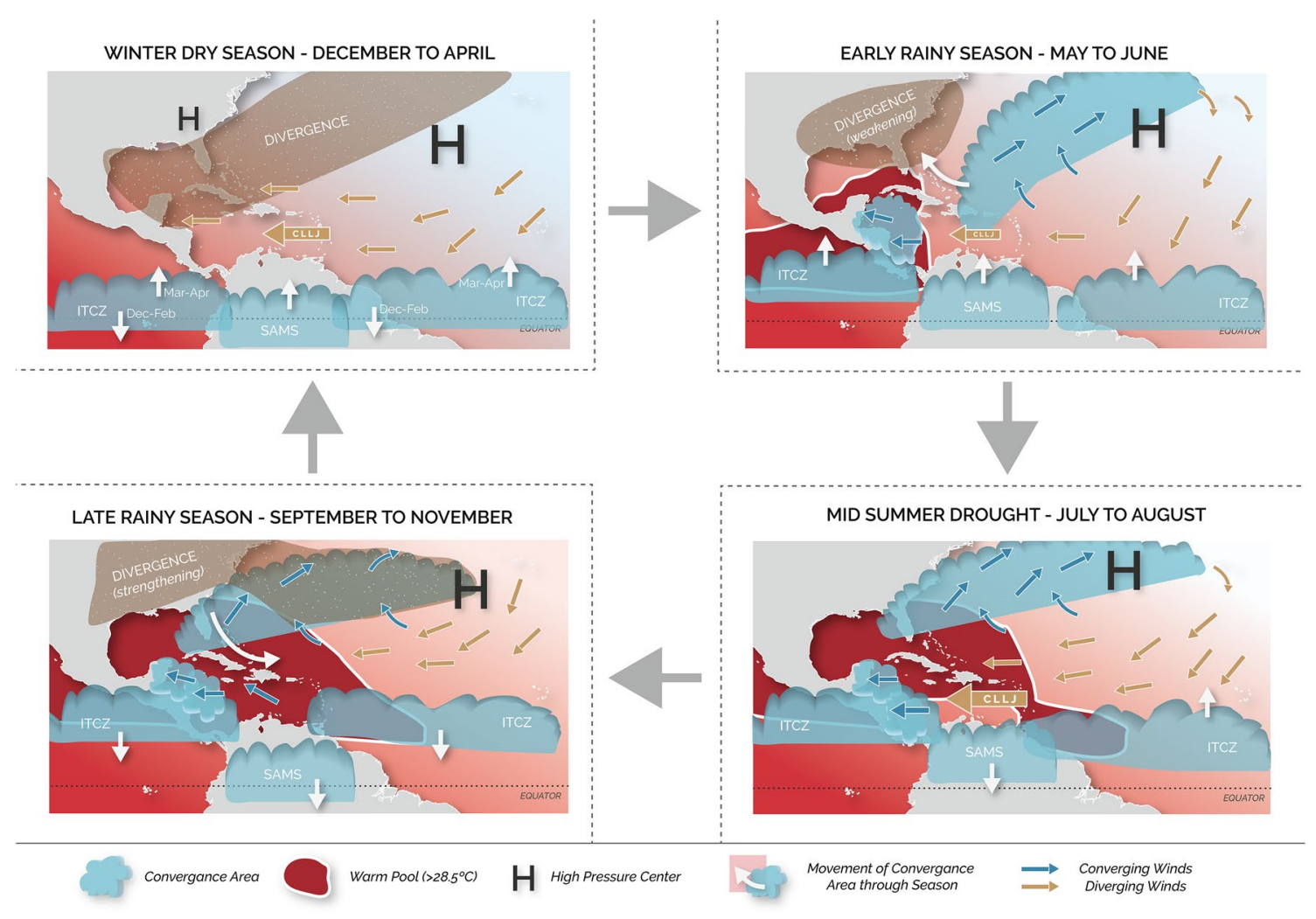

Fig. 8 Schematic of the features associated with the seasonal cycle of rainfall over the Caribbean. Areas shaded in blue are the convergence bands. Areas in brown denote transient divergence. White arrows denote their movement during a given season. Shaded blue and brown arrows denote the convergent and divergent wind vectors, respectively. The large "H" denotes the North Atlantic Subtropical High. The small " $H$ " denotes the continental High. The warm pool denotes SSTs greater than $28.5^{\circ} \mathrm{C}$ is highlighted in maroon 
climatological features across these regions throughout the seasonal cycle evolution.

1. During the WDS, NASH influence on the Caribbean is strong. The North Atlantic anticyclone connects with the continental North American High and provides strong diverging trade winds and subsidence in the Caribbean. The WDS-CLLJ, an absence of the AWP, and strong mid-latitude features from the U.S. mainland enhance divergence in the CS, Caribbean, and NW Caribbean, respectively. The southern flank of NASH expands southward as the ITCZ migrates southward. The southward migration of the Atlantic ITCZ draws moisture to South America (i.e. to the Guianas) during the beginning of the WDS.

2. During the transition into the ERS, the NASH breaks off from the dissipating continental High. As a result, the western flank of the high-pressure cell emerges and induces converging low-level southeasterly winds from the CS to the mid-latitudes which breaks the influence of the diverging trade winds and wintertime CLLJ and produces uplifting and rainfall. In addition, the Atlantic and Eastern Pacific ITCZ begins its northward migration. During the ERS, the western flank of NASH expands westward and brings excess rainfall over evaporation to the central and NW Caribbean. The mid-latitude features over the continental U.S. and their divergence retreat northward. The Eastern Pacific ITCZ migrates northward and affects the Western Caribbean. The expanding western flank of NASH interacts with the northward migrating Eastern Pacific ITCZ to transport moisture to the NW Caribbean through its shifting easterly to southeasterly winds. Simultaneously, the AWP emerges across the western CS and Gulf of Mexico and enhances the moisture convergence provided by the Eastern Pacific ITCZ and the western flank of NASH. The Atlantic ITCZ migrates into the Guianas and its absence, which is accompanied by strong divergent lowlevel trade winds from the northward shifting southern flank of NASH, inhibits the ERS in the Lesser Antilles. The low-level trade winds re-intensify and re-infiltrate the Caribbean as NASH strengthens, which results in the MSD.

3. During the MSD, NASH expands westward and shifts northwestward. This cuts off moisture transport into the Caribbean as mass divergence and subsidence associated with the trade winds return. This causes an enhanced MSD in the NW Caribbean. The Eastern Pacific ITCZ migrates northward into Central America and buffers the extent of the MSD in the Western Caribbean. The Atlantic ITCZ migrates into the Lesser Antilles. The U.S. mid-latitude features are absent. The AWP expands to all but the colder ocean waters of the North South
American coastline, causes a strong meridional SST gradient in the CS, and enhances the NASH-SST feedback loop and resultant MSD-CLLJ. The CLLJ enhances divergence across the central and eastern CS and convergence in the Nicaraguan to Costa Rican coastlines of the Western Caribbean. The MSD transitions into the LRS as NASH begins its western flank contraction.

4. During the LRS, NASH contracts and its western flank migrates southeast. The Eastern Pacific ITCZ begins its southward migration and its interaction with the western flank of NASH returns as low-level southeasterly winds return across the CS. However, U.S. mainland mid-latitude features and its divergence rapidly shift southward and weaken the convergence on the western flank of NASH and its confluent interactions with the Eastern Pacific ITCZ. The Atlantic ITCZ reaches its northern most extent in the Lesser Antilles and begins its southward migration. The AWP, which is at its largest spatial coverage, begins to contract and enhances moisture convergence across the Caribbean. The CLLJ disappears as the combination of returning southeasterlies and warmer SSTs in the central CS reduces the NASH-SST feedback loop. NASH continues to contract until the continental High emerges, which results in the dissipation of its western flank, intensification of the trade winds in the $\mathrm{CS}$, and the beginning of the WDS.

The schematic provides several important insights addressing previous literature on the dynamical mechanisms of Caribbean rainfall. First, the structure of the ERS Caribbean Rain Belt (CRB) theorized by Allen and Mapes (2017), is similar to the ERS in this study and appears to return during the LRS. Second, the pattern of the U.S transient divergence suggests the migration pattern of mid-latitude troughs in the Caribbean and continental U.S: gradual decline in its frequency during the ERS, and abrupt incline in its frequency during the LRS (DiMego et al. 1976). DiMego et al. (1976) also suggests that during the spring these features stall in the Caribbean, whereas in the fall they quickly pass through; therefore, the convergence bands in the NW and Western Caribbean may be influenced by the stalling of convergence by the right flank of mid-latitude troughs, a notion similarly suggested in Allen and Mapes (2017). The greater frequency of mid-latitude features in the Caribbean during the LRS and WDS may explain why transient divergence infiltrates the Caribbean quickly, which is synonymous with subsidence behind cold surges (Reding 1992; Schultz et al. 1998; Giannini et al. 2000; Sáenz and Durán-Quesada 2015). Finally, tropical cyclones and easterly waves have marginal influences in the climatological Caribbean rainfall cycle, which is in contrast with several studies (Taylor et al. 2002; Herrera et al. 2015), and are not shown in the schematic. 
This study finds several distinctive characteristics in the Caribbean and Caribbean climate regions that are not seen in earlier Caribbean regional classification studies that use monthly or longer averaged datasets. For instance, this study finds the NW Caribbean to have a bimodal pattern with portions of the region having a prominent MSD, and most of the Lesser Antilles to have a unimodal rainfall pattern. This differs from Jury et al. (2007) where they describe the NW Caribbean as unimodal with bimodality increasing in magnitude from the NW Caribbean to the Lesser Antilles. This also differs from Chen and Taylor (2002) and Giannini et al. (2000) who describe the entire Caribbean as having a bimodal rainfall pattern. Hence, the differences are likely due to longer time averages in previous studies which mask the sub-monthly rainfall transitions that this temporally finer study finds. Overall, this study demonstrates the importance of using greater temporal resolution in order to distinguish rainfall characteristics in the Caribbean. Although it is apparent regional and large-scale dynamics are the major contributors of the rainfall cycle in the Caribbean, given the limited station data available in the region we cannot fully evaluate the role that the local forcings may play in the higher-resolution spatial detail of seasonal rainfall.

Finally, this study provides a framework for investigating the variability and change of the rainfall cycle in the Caribbean. Future work will investigate the interannual variability of the onset and demise of the rainfall cycles while using the same moisture budget framework in order to deduce the extent to which the climatological local, regional, and largescale processes found in this study play a role in influencing hydro-meteorological disasters (i.e. droughts and floods) in the Caribbean. Further work investigating the interannual to multidecadal variability of the rainfall cycle in the Caribbean could be done to delineate the observed influences that interannual to multidecadal phenomena (i.e. El Nino Southern Oscillation, North Atlantic Oscillation, Atlantic Multidecadal Oscillation) have on precipitation in the region (Malmgren et al. 1998; Giannini et al. 2000; Chen and Taylor 2002; Mapes et al. 2005). Hence, this study provides the foundation for advancing in the predictability of the rainfall cycle in the Caribbean. The classification of the dynamical mechanisms and processes that dictate the specific rainfall regions of the Caribbean in this study can be used to predict the seasonal rainfall cycle, the genesis of hydro-meteorological disasters, and the modified climatological effects stemming from large-scale phenomena.

Acknowledgements The authors would like to thank Elisabeth Gawthrop for helping create the schematic. We would also like to thank Alessandra Giannini, Ángel Munoz, Teddy Allen, and Cédric Van Meerbeeck for useful discussions. We would also like to thank the Caribbean Institute for Meteorology and Hydrology (CIMH) and the National Oceanic Atmospheric Administration (NOAA) for providing the data, and the European Centre for Medium-Range Weather Forecasts for the ERA-Interim Reanalysis. CM would like to thank NOAA for funding through the International Research and Applications Project (IRAP). Finally, we would like to thank the insightful and constructive comments from the reviewers.

OpenAccess This article is distributed under the terms of the Creative Commons Attribution 4.0 International License (http://creativeco mmons.org/licenses/by/4.0/), which permits unrestricted use, distribution, and reproduction in any medium, provided you give appropriate credit to the original author(s) and the source, provide a link to the Creative Commons license, and indicate if changes were made.

\section{References}

Agudelo P, Hoyos C, Curry J, Webster P (2011) Probabilistic discrimination between large-scale environments of intensifying and decaying African easterly waves. Clim Dyn 36:1379-1401

Allen TL, Mapes BE (2017) The late spring Caribbean rain-belt: climatology and dynamics. Int J Climatol 37:4981-4993

Amador JA (1998) A climatic feature of the tropical Americas: the trade wind easterly jet. Top Meteor Oceanogr 5(2):1-13

Amador JA, Magaña VO, Perez JB (2000) The low level jet and convective activity in the Caribbean. Preprints 24th Conference in hurricanes and tropical meteorology. American Meteorological Society, Fort Lauderdale, 114-115

Angeles ME, González JE, Ramírez-Beltrán ND, Tepley CA, Comarazaour DE (2010) Origins of the Caribbean rainfall bimodal behavior. J Geophys Res 115(D11):D11106

Bovolo CI, Pereira R, Parkin G, Kilsby C, Wagner T (2012) Finescale regional climate patterns in the Guianas, tropical South America, based on observations and reanalysis data. Int J Climatol 32:1665-1689

Brubaker KL, Entekhabi A, Eagleson PS (1993) Estimation of continental precipitation recycling. J Clim 6(6): 1077-1089

Burpee RW (1972) The origin and structure of easterly waves in the lower troposphere of North Africa. J Atmos Sci 29:77-90

Carlson TN, Prospero JM (1972) The large-scale movement of Saharan air outbreaks over the northern equatorial Atlantic. J Appl Meteorol 11(2):283-297

Chen AA, Taylor MA (2002) Investigating the link between early season Caribbean rainfall and the El Niño+ 1 year. Int J Climatol 22:87-106

Cook KH, Vizy EK (2010) Hydrodynamics of the Caribbean low level jet and its relationship to precipitation. J Clim 23:1477-1494

Curtis S, Gamble DW (2007) Regional variations of the Caribbean mid-summer drought. Theor Appl Climatol 94(1-2):25-34

Davis RE, Hayden BP, Gay DA, Phillips WL, Jones GV (1997) The North Atlantic subtropical anticyclone. J Climate 10:728-744

Dee D et al (2011) The ERA-Interim reanalysis: Configuration and performance of the data assimilation system. Q J R Meteorological Soc 137: 553-597

DiMego GJ, Bosart LF, Enderson GW (1976) An examination of the frequency and mean conditions surrounding frontal incursions into the Gulf of Mexico and Caribbean Sea. Mon Weather Rey 104:709-718

Dunion JP (2011) Rewriting the climatology of the tropical North Atlantic and Caribbean Sea atmosphere. J Clim 24(3):893-908

Durán-Quesada AM, Gimeno L, Amador JA, Nieto R (2010) Moisture sources for Central America: identification of moisture sources using a Lagrangian analysis technique. J Geophys Res 115:D05103 
Durán-Quesada AM, Reboita M, Gimeno L (2012) Precipitation in tropical America and the associated sources of moisture: a short review. Hydrol Sci J 57(4):612-624

Eichhorn A, Bader J (2017) Impact of tropical Atlantic sea-surface temperature biases on the simulated atmospheric circulation and precipitation over the Atlantic region: an ECHAM6 model study. Clim Dyn 49:2061-2075

Food and Agriculture Organization of the United Nations (FAO) (2016) Situation report: dry corridor in Central America. FAO, pp 3

Gamble DW, Parnell DB, Curtis S (2007) Spatial variability of the Caribbean mid-summer drought and relation to North Atlantic high circulation. Int J Climatol 28(3):343-350

Giannini A, Kushnir Y, Cane M (2000) Interannual variability of Caribbean rainfall, ENSO, and the Atlantic Ocean. J Clim 13:297-311

Hamada JI, Yamanaka MD, Matsumoto J, Fukao S, Winarso PA, Sribimawati T (2002) Spatial and temporal variations of the rainy season over Indonesia and their link to ENSO. J Meteorol Soc Jpn 80:285-310

Hastenrath S (2002) The intertropical convergence zone of the eastern Pacific revisited. Int J Climatol 22:347-356

Henderson-Sellers A, Robinson PJ (1986) Contemporary climatology. Longman, New York, 439 pp

Herrera E, Magaña V, Caetano E (2015) Air-sea interactions and dynamical processes associated with the midsummer drought. Int J Climatol 35:1569-1578

Hidalgo HG, Durán-Quesada AM, Amador JA, Alfaro EJ (2015) The Caribbean Low-Level Jet, the InterTropical Convergence Zone and precipitation patterns in the Intra-Americas Sea: a proposed dynamical mechanism. Geografiska Annaler Ser A Phys Geogr 97:41-59

Huang H-PR, Seager Y, Kushnir (2005) The 1976/77 transition in precipitation over the Americas and the influence of tropical sea surface temperature. Clim Dyn 24:721-740

Huffman GJ, Adler RF, Bolvin DT, Gu G, Nelkin EJ, Bowman KP, Hong Y, Stocker EF, Wolff DB (2007) The TRMM multi-satellite precipitation analysis: quasi-global, multi-year, combinedsensor precipitation estimates at fine scale. J Hydrometeorol $8(1): 38-55$

Inoue M, Handoh IC, Bigg GR (2002) Bimodal distribution of tropical cyclogenesis in the Caribbean: Characteristics and environmental factors. J Clim 15:2897-2905

Jin FJ, Zangvil A (2010) Relationship between moisture budget components over the eastern Mediterranean. Int J Climatol 30(5):733-742

Jury M, Malmgren BA, Winter A (2007) Subregional precipitation climate of the Caribbean and relationships with ENSO and NAO. J Geophys Res 112:D16107

Lewsey C, Cid G, Kruse. E (2004) Assessing climate change impacts on coastal infrastructure in the Eastern Caribbean. Mar Policy 28:393-409

Magaña V, Amador JA, Medina S (1999) The midsummer drought over Mexico and Central America. J Clim 12(6):1577-1588

Maldonado T, Alfaro E, Hidalgo H (2018) Revision of the main drivers and variability of Central America climate and seasonal forecast systems. Rev Biol Trop 66:153-175

Malmgren BA, Winter A, Chen D (1998) El Niño Southern oscillation and North Atlantic oscillation control of climate in Puerto Rico. J Clim 12(4):977-985

Mapes BE, Liu P, Buenning N (2005) Indian monsoon onset and the Americas midsummer drought: out-of-equilibrium responses to smooth seasonal forcing. J Clim 18:1109-1115

Misra V, Li H, Kozar M (2014) The precursors in the intra-Americas seas to seasonal climate variations over North America. J Geophys Res (Oceans) 119(5):2938-2948

Mitchell T, Wallace JM (1992) The annual cycle in equatorial convection and sea surface temperature. J Clim 5:1140-1156
Moron V, Gouirand I, Taylor M (2015) Weather types across the Caribbean basin and their relationship with rainfall and sea-surface temperatures. Clim Dyn 47:601-621

Mote TL, Ramseyer CA, Miller PW (2017) The Saharan Air Layer as an early rainfall season suppressant in the eastern Caribbean: the 2015 Puerto Rico drought. J Geophys Res Atmos 122(10):966-910,982

Muñoz E, Busalacchi AJ, Nigam S, Ruiz-Barradas A (2008) Winter and summer structure of the Caribbean low-level jet. J Clim 21(6):1260-1276

National Oceanic and Atmospheric Administration the Climate Global Hazards (2005) "State of the Climate Global Hazards" National Climatic Data Center. http://www.ncdc.noaa.gov/sotc/hazar ds/2005/jul. Accessed July 2005

Office of Disaster Preparedness and Emergency Management (ODPEM) (2010) "133 Communities impacted by Nicole." Jamaica Observer. http://www.jamaicaobserver.com/news/133communities- impacted-by-Nicole. 2 Oct 2010

Pomposi C, Kushnir Y, Giannini A (2015) Moisture budget analysis of SST-driven decadal Sahel precipitation variability in the twentieth century. Clim Dyn 44:3303-3321

Poveda G, Mesa O (2000) On the existence of Lloro (the rainiest locality on Earth): enhanced ocean-land-atmosphere interaction by a low level jet. Geophys Res Lett 27(11):1675-1678

Reding PJ (1992) The Central American Cold Surge: an observational analysis of the deep southward penetration of North America Cold Fronts. MSc. thesis, Department of Meteorology, Texas A\&M University

Rudloff W (1981) World-climates, with tables of climatic data and practical suggestions. Wissenschaftliche Verlagsgesellschaft $\mathrm{mbH}$, Stuttgart

Ryu J-H, Hayhoe K (2013) Understanding the sources of Caribbean precipitation biases in CMIP3 and CMIP5 simulations. Clim Dyn 42(11-12):3233-3252

Sáenz F, Durán-Quesada AM (2015) A climatology of low level wind regimes over Central America using a weather type classification approach. Front Earth Sci 3:15

Schultz DM, Bracken WE, Bosart LF (1998) Planetary- and synopticscale signatures associated with Central American Cold Surges. Mon Weather Rev 126:5-27

Seager R, Henderson N (2013) Diagnostic computation of moisture budgets in the ERA-interim reanalysis with reference to analysis of CMIP-archived atmospheric model data. J Cim 26:7876-7901

Seager R, Naik N, Vecchi GA (2010) Thermodynamic and dynamic mechanisms for large-scale changes in the hydrological cycle in response to global warming. J Clim 23:4651-4668

Shaw B (1987) An analysis of the rainfall regimes on the coastal region of Guyana. J Climatol 7:291-302

Silva V, Kousky VE (2012) The South American Monsoon System: Climatology and Variability. In: Shih-Yu W (ed) Modern climatology. InTech, London (ISBN: 978-953-51-0095-9)

Simpson MC, Scott D, Harrison DM et al (2010) Quantification and magnitude of losses and damages resulting from the impacts of climate change: modelling the transformational impacts and costs of sea level rise in the caribbean (full document). United Nations Development Program (UNDP), Barbados

Stephenson TS et al (2014) Changes in extreme temperature and precipitation in the Caribbean region, 1961-2010. Int J Climatol 34:2957-2971. https://doi.org/10.1002/joc.3889

Taylor MA, Alfaro EJ (2005) Central America and the Caribbean, Climate of. In: Oliver JE (ed) Encyclopedia of world climatology. Encyclopedia of earth sciences series. Springer, Dordrecht

Taylor MA, Enfield DB, Chen AA (2002) Influence of the tropical Atlantic versus thetropical Pacific on Caribbean rainfall. J Geophys Res 93:485-498 
Taylor MA, Stephenson TS, Chen A, Stephenson K (2012) Climate change and the Caribbean: review and response. Caribb Stud 40(2):169-200

Toma V, Webster P (2010) Oscillations of the intertropical convergence zone and the genesis of easterly waves. part I: diagnostics and theory. Clim Dyn 34:587-604. https://doi.org/10.1007/s0038 2-009-0584-X

Trenberth KE, Guillemot CJ (1995) Evaluation of the global atmospheric moisture budget as seen from analysis. J Clim 8:2255-2272

United Nations Office for the Coordination of Humanitarian 880 Affairs (OCHA) (2015) Drought in Central America in 2015 (as for October 6, 2015)

United Nations Office for the Coordination of Humanitarian 880 Affairs (OCHA) (2016) Humanitarian bulletin: Haiti, June 2016, 62: 5-6

Waliser DE, Gautier C (1993) A satellite-derived climatology of the ITCZ. J Clim 6:2162-2174

Wang C (2007) Variability of the Caribbean low-level jet and its relations to climate. Clim Dyn 29:411-422

Wang C, Enfield DB (2001) The tropical Western Hemisphere warm pool. Geophys Res Lett 28:1635-1638
Wang C, Lee S-K (2007) Atlantic warm pool, Caribbean low-level jet, and their potentialimpact on Atlantic hurricanes. Geophys Res Lett 34:L02703

Wang C, Enfield DB, Lee S-K, Landsea CW (2006) Influences of the Atlantic warm pool on Western Hemisphere summer rainfall and Atlantic hurricanes. J Clim 19:3011-3028

Wang CS-K, Lee, Enfield DB (2008) Climate response to anomalously large and small Atlantic warm pools during the summer. J Clim $21: 2437-2450$

Weisberg RH (1996) On the evolution of SST over the PACS region. In: Abstracts of 76th AMS annual meeting, Atlanta, Georgia, Amer. Meteor. Soc., p 378

Zhang C (2001) Double ITCZs. J Geophys Res 106(D11):11785-11792

Publisher's Note Springer Nature remains neutral with regard to jurisdictional claims in published maps and institutional affiliations. 